\title{
Dictynna
}

Dictynna

Revue de poétique latine

$11 \mid 2014$

Varia

\section{Trajectoire épique en an(n)amorphose (Ovide, Fastes, III, 545-656)}

\section{Gilles Tronchet}

\section{Q OpenEdition}

Journals

Édition électronique

URL : http://journals.openedition.org/dictynna/1097

DOI : 10.4000/dictynna.1097

ISSN : 1765-3142

\section{Référence électronique}

Gilles Tronchet, «Trajectoire épique en an(n)amorphose (Ovide, Fastes, III, 545-656) », Dictynna [En ligne], 11 | 2014, mis en ligne le 19 décembre 2014, consulté le 10 septembre 2020. URL : http:// journals.openedition.org/dictynna/1097 ; DOI : https://doi.org/10.4000/dictynna.1097

Ce document a été généré automatiquement le 10 septembre 2020.

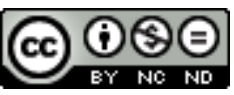

Les contenus des la revue Dictynna sont mis à disposition selon les termes de la Licence Creative Commons Attribution - Pas d'Utilisation Commerciale - Pas de Modification 4.0 International. 


\title{
Trajectoire épique en an(n)amorphose (Ovide, Fastes, III, 545-656)
}

\author{
Gilles Tronchet
}

\section{1- Jalons d'un itinéraire textuel}

1 Anna, sœur de Didon, second rôle fugace de l'Énéide, est devenue dans les Fastes une héroïne fugitive, condamnée au voyage par l'incessante instabilité de son destin ${ }^{1}$. Dans cette œuvre où Ovide rattache les rites et les fêtes de la Rome augustéenne aux récits de leurs origines, elle est paradoxalement requise pour motiver le culte à Rome d'une déesse dont le nom incarne la permanence, Anna Perenna ${ }^{2}$.

Divinité mineure du Latium, celle-ci était vraisemblablement une protectrice de la fécondité3. La célébration d'Anna Perenna, qu'Ovide situe à la date du 15 mars, était l'occasion de réjouissances et de beuveries près du Tibre, dont un tableau très coloré est offert en préambule aux développements étiologiques $\left(F\right.$. III, 523-544) ${ }^{4}$. Le poète s'applique ensuite à motiver le rituel, qu'il relie à l'identité de la déesse, avec une abondance d'explications qui ne va pas sans éveiller l'incertitude, puisque, sur plus de cent cinquante vers, il n'offre pas moins de six options concurrentes. Il en privilégie deux, qui font l'objet d'une anecdote circonstanciée, d'abord celle de la princesse carthaginoise en exil, accueillie par Énée (F. III, 545-656), puis, selon un contraste manifeste, celle d'une vieille femme plébéienne qui, bien plus tard, aurait nourri les Romains lors de l'invasion gauloise, avant de ridiculiser Mars, en se faisant passer pour Minerve, dont le dieu de la guerre était amoureux (F. III, 661-696) ${ }^{5}$.

Mais la solution qui est surtout mise en relief, à la fois parce qu'elle est fournie d'emblée et qu'elle reçoit le plus long développement, consiste à identifier Anna Perenna avec la figure virgilienne : chassée de Carthage après la mort de Didon, elle aurait, à l'issue de maintes tribulations, abordé sur les rivages du Latium et, enlevée 
finalement par le dieu d'un cours d'eau, le Numicius, aurait été métamorphosée en nymphe.

4 Or, il se trouve que le déroulement de ces aventures s'appuie non seulement sur de nombreuses pistes fournies par l'Énéide, mais suit un schéma analogue à la geste d'Énée. Cependant, les circonstances de cette histoire, outre la dimension beaucoup plus réduite du récit qui les contient, présentent de nombreux décalages avec celles qui permettent chez Virgile d'édifier à mesure le portrait exemplaire d'un héros. C'est à un jeu de réécriture distanciée que se livre Ovide, lorsqu'il restitue, comme à travers une lentille déformante, dans une autre sphère générique, celle d'une œuvre composée en distiques élégiaques, l'équivalent d'un périple épique.

5 Il est d'autant plus intéressant d'observer un tel récit en détail que, de manière frappante, les Fastes n'évoquent à aucun endroit les voyages d'Énée lui-même, tels que les avait récemment illustrés l'épopée de Virgile: on aurait pu s'attendre à ce que l'installation dans le Latium du héros troyen, auquel Albe puis Rome doivent leur fondation, soit au moins relatée. Mais il est notable que le personnage n'occupe dans les Fastes qu'une place fort modeste, lors même qu'il correspond, de pair avec Romulus, à un modèle augustéen par excellence ${ }^{6}$ : un seul bref récit commémore l'un de ses exploits, le combat contre Mézence (IV, 877-900)7. D'ailleurs, il n'est mis en scène qu'une fois établi sur les rives du Tibre. C'est comme un substitut aux errances d'Énée qu'Ovide a pris soin d'intégrer dans les Fastes, avec le périple d'Anna, qui la mène de Carthage en Italie, débouchant sur des retrouvailles avec le héros virgilien, marié désormais à Lavinia.

Comme les critiques l'ont bien des fois souligné, la configuration de cet épisode reprend le modèle narratif de l'Énéide, mais selon une version très abrégée, de sorte que le récit ovidien est en général caractérisé comme une épopée en miniature, exercice alexandrin qui intègre cette histoire à la manière d'un emblema dans la mosaïque élégiaque des Fastes. En outre, la brièveté d'une telle réplique et le décalage de tonalité qui l'accompagne incitent souvent à l'envisager comme un travestissement ou une parodie ${ }^{8}$. On évitera dans ces pages le recours à de telles catégories, parce qu'elles ont l'inconvénient de figer en une formule simplificatrice la complexité mouvante de la réécriture ovidienne, dont on s'efforcera plutôt, grâce à une analyse attentive, de cerner les divers effets.

Quand Ovide s'appuie sur les principes de la narration épique et s'en démarque à la fois, une double dimension en découle : d'une part, une élaboration originale propre aux Fastes, où Anna reçoit un statut ambivalent, celui d'une héroïne paradoxale, entièrement soumise à des forces qui s'acharnent sur elle, sans autre issue que la métamorphose ultime qui la soustrait à une avalanche d'épreuves insurmontables; d'autre part, un éclairage porté par contrecoup sur l'œuvre antécédente, du fait que la figure d'Énée, sans cesse impliquée par métonymie en regard d'Anna, selon une série d'analogies et de contrastes, se trouve interrogée ainsi que les valeurs dont elle est porteuse. L'examen débouche sur la saisie d'une entreprise poétique décalée, qu'illustre le personnage de la voyageuse, bien peu faite pour incarner l'héroïsme. Il laisse non moins transparaitre, avec la mise à l'écart de références idéologiques chères au régime augustéen, la constitutive implication d'une ironie latente, lors même qu'un objectif proclamé des Fastes était d'accomplir, au fil du calendrier, une célébration du pouvoir impérial9. 
8 Avec l'histoire d'Anna, le poète, tout en se plaçant dans la continuité du récit virgilien, bâtit une fiction comme en marge de son modèle, dont la leçon glorificatrice est du même coup relativisée. Il se fonde sur une étiologie fantaisiste, procédant par un jeu d'homonymie qui permet d'identifier à la déesse romaine, Anna Perenna, un personnage lié, dans l'Énéide, à un drame qui jette quelque ombre sur le prestigieux destin du héros, la mort de Didon ${ }^{10}$. Corrélativement, la figure d'Énée, confronté dans les Fastes à la sœur de la femme dont il a causé le suicide, va faire l'objet d'une approche latérale, selon une démarche récurrente dans les œuvres d'Ovide. En effet, chaque fois que celles-ci évoquent avec quelque ampleur la geste d'Énée, c'est en reléguant le personnage au second plan, lui retirant son statut de héros épique, voyageur ou guerrier, pour le subordonner à une figure féminine : déjà, dans la septième Héroïde, il n'est que le destinataire des reproches que lui adresse Didon, juste avant qu'elle se tue ; puis, dans les livres XIII et XIV des Métamorphoses, où son périple fournit une toile de fond à l'enchaînement de transformations surnaturelles, lorsqu'il participe à un épisode, c'est comme auditeur du récit fait par la Sibylle (XIV, 101-157), et finalement, lors de sa propre apothéose, comme l'objet de la sollicitude maternelle déployée par Vénus (XIV, 581-607) ${ }^{11}$. Un tel effacement se retrouve dans l'histoire d'Anna où, de héros, le chef troyen est ramené à la fonction d'auxiliaire, accordant à la naufragée une hospitalité qu'il ne sera pas même capable de garantir contre la jalousie effrénée de son épouse, Lavinia.

9 Pourtant Ovide se montre un assidu lecteur de l'épopée, à laquelle il emprunte maintes formules, dont il prolonge les pistes avec une attention aussi minutieuse qu'inventive ${ }^{12}$. Par contre il laisse de côté le principe unitaire d'une destinée promise au héros et l'aura qui en découle pour celui-ci. Relégué au second plan dans les Métamorphoses, Énée se trouve sensiblement dévalorisé dans l'épisode des Fastes, où son interférence avec les aventures d'Anna cristallise une contestation ludique des hiérarchies. Une telle tendance est confirmée dans un autre registre par l'histoire qui suit, offrant une étiologie concurrente où Anna de Bovillae, la "gentille petite vieille", comis anus (III, 684), en fausse entremetteuse, berne le dieu Mars ${ }^{13}$. Davantage, l'ampleur du double développement offert pour mettre en scène, selon deux versions disparates, une divinité mineure telle qu'Anna Perenna contraste avec le bref passage destiné à commémorer le meurtre de Jules César et son apothéose, circonstance pourtant décisive, qui occupait la même place dans le calendrier, le 15 mars (III, 697-710) ${ }^{14}$.

Dans ce contexte, le recours à un canevas épique afin d'évoquer les tribulations d'un personnage dépourvu de prestige, comme une copie en creux de l'Énéide, acquiert une incidence notable. Pour en dégager les contrecoups sémantiques, l'analyse va tour à tour adopter quatre axes d'observation. Tout d'abord, il s'agit de repérer les jalons diégétiques puisés dans le modèle par le poète qui les réinvestit d'une autre manière. Puis il convient de détailler les correspondances entre les histoires respectives d'Anna et du héros troyen, appuyées sur maintes réminiscences textuelles, de façon à mettre en lumière le jeu d'homologie et de différenciation qui se développe. Ensuite il importe de manifester la distance qu'une telle réécriture en anamorphose, contestant sur un mode implicite les valeurs associées à l'épopée, entraîne vis-à-vis de celle-ci. Enfin il sera possible de mieux cerner la dimension esthétique de l'entreprise, en montrant comment l'intrication d'une influence élégiaque aux références épiques fait vaciller les frontières entre les genres, tout en se reliant à un agencement plus étendu, qui organise le livre III des Fastes. 


\section{2- Une voie offerte par l'Énéide}

11 À première vue, l'histoire d'Anna pourrait être envisagée comme un supplément aux Métamorphoses, une transformation surnaturelle que sa valeur étiologique a fait mettre en réserve pour les Fastes ${ }^{15}$. Cependant, la manière dont l'épisode est traité, comme un complément aux récits de l'Énéide, oriente la lecture vers une confrontation avec ce modèle particulier et, à travers lui, avec le genre auquel il se rattache. De fait, ce sont les errances d'une longue navigation et la quête, à l'issue, d'un séjour définitif, qui président aux aventures d'Anna, comme à celles d'Énée, dont le principe remonte à l'histoire d'Ulysse chez Homère. Ainsi la dynamique des événements racontés suit le schéma qui caractérise l'épopée, avec un déséquilibre initial, impliquant un vaste périple et conduisant à un nouvel équilibre, même si, en l'occurrence, la métamorphose finale de l'héroïne en divinité aquatique déroge à la norme ${ }^{16}$.

12 En outre, comme Ovide mobilise des lieux et des personnages issus de l'œuvre virgilienne, il installe résolument l'anecdote dans un cadre légendaire préexistant. La trajectoire d'Anna relie Carthage au Latium, deux sites décisifs dans le parcours d'Énée, la voyageuse étant tour à tour mise en relation avec deux trios de personnages présents dans l'Énéide. Les premiers déterminent sa fuite: Didon, par son suicide, elle dont les cendres maintiennent un reste de présence, le prince numide Iarbas, qui envahit Carthage, enfin Pygmalion, le frère haineux, qui la persécute. Elle trouve les seconds lors de son arrivée en Italie : Énée lui-même, accompagné du fidèle Achate, puis son épouse, Lavinia ${ }^{17}$.

Bien plus, l'enchaînement des circonstances qui amorcent le récit des Fastes repose, pour une bonne part, sur les scènes de l'Énéide où Anna est impliquée, s'inspirant même des paroles qui lui sont prêtées ${ }^{18}$. Les corrélations se multiplient avec le récit virgilien, conférant du même coup à celui-ci une aptitude proleptique. Anna soulignait devant sa sœur le dépit de Iarbas, prétendant repoussé, l'associant au risque d'une attaque des Numides contre Carthage dont Énée pourrait seul garantir la sécurité (En. IV, 35-43) : la ville, aussitôt après la mort de la reine, subit l'occupation et Iarbas tient sa revanche ( $F$. III, 551-554) ${ }^{19}$; elle évoquait les menaces que faisait régner Pygmalion (En. IV, 43-44) : à son tour, elle s'y trouve exposée (F. III, 577-580 $)^{20}$. Et puisque Battus, son hôte, refuse de la protéger, elle est forcée de reprendre la mer. Cette fois, c'est un monologue de Didon que le v. 579, marquant ce nouveau départ, rappelle diffusément ${ }^{21}$ : la reine, sachant qu'Énée était sur le point de lever l'ancre, se demandait si elle devait accompagner les Troyens, et déplorait que sa sœur l'ait convaincue de céder à sa passion pour le héros. Juste avant le départ, Ovide intègre un motif qui est commun à ce passage et au premier discours d'Anna, le respect voué aux cendres. La reine s'accusait finalement d'avoir trahi la loyauté due à celles de son défunt époux (En. IV, 552), alors que sa sœur avait soutenu d'emblée que les restes de Sychée ne pouvaient être sensibles à un éventuel remariage (En. IV, 34). Anna se comporte dans l'histoire des Fastes comme si les remords de sa sœur l'avaient amenée à changer elle-même d'attitude : c'est après avoir rendu un ultime hommage aux cendres de la reine, qu'elle embarque pour l'exil (F. III, 561-564).

Plusieurs autres éléments du récit virgilien, susceptibles d'avoir influé sur le scénario adopté par Ovide, établissent un faisceau de menues correspondances, jouant chacune toutefois sur un décalage de situation. 
15 De la sorte, quand Didon, ne réussissant pas à fléchir Énée, a voulu envoyer sa sœur auprès de lui comme messagère, elle insistait sur la facilité qu'avait Anna pour communiquer avec lui (En. IV, 421-423) ${ }^{22}$ : or, par une frappante coïncidence, l'héroïne, que son naufrage vient de jeter sur les côtes du Latium, rencontre d'abord Énée ${ }^{23}$; celui-ci, tout disposé à la recueillir, lui adresse aussitôt la parole et lui confie ses regrets de n'avoir pas prévu que la reine se donnerait la mort ${ }^{24}$. On serait tenté d'envisager aussi comme une virtuelle préfiguration l'un des ordres ultimes de Didon, que la nourrice de Sychée doit transmettre à Anna: il faut que celle-ci, pour préparer un sacrifice expiatoire, s'asperge le corps d'une eau puisée dans une rivière, fluuiali... lympha (En. IV, 635), exigence que, dans le récit des Fastes, son enlèvement par le Numicius va satisfaire au-delà de toute mesure.

Ovide introduit également des échos allusifs aux dernières paroles de Didon, juste avant son suicide. La reine, en rappelant combien le sort l'avait favorisée avant qu'arrivent les Troyens, se qualifiait à deux reprises de felix (En. IV, 657). Quand Anna est accablée par une terrible tempête, le récit, recourant à la figure épique du makarismos, reprend l'adjectif, non sans une ironie grinçante, puisqu'il concerne à présent la défunte : sa sœur l'estime heureuse d'avoir péri plutôt que de subir une telle épreuve $(F . \text { III, 597 })^{25}$. Aussitôt après dans le passage de Virgile, Didon acceptait de mourir sans obtenir de vengeance, moriemur inultae (En. IV, 659). Chez Ovide, un énoncé analogue, moins empreint, il est vrai, de résignation, s'applique à Lavinia : dans sa folie haineuse contre Anna, dont les symptômes ne sont pas sans rappeler la violente rancune de Didon contre Énée, elle en vient à souhaiter la mort, à condition d'être vengée, cupit ulta mori (F. III, 638) ${ }^{26}$.

17 Cette volonté farouche conduit au dénouement de l'épisode ovidien, dont la logique s'annonçait par ailleurs chez Virgile dans l'exclamation de douleur que pousse Anna devant le corps de Didon : exstinxti te meque, soror ("en éteignant ta vie, tu as éteint la mienne, ma sœur", En. IV, 682) ${ }^{27}$. Une telle hyperbole ouvre la voie d'une solidarité entre le destin des deux femmes et débouche sur leur réunion par delà le trépas, sorte de programme latent pour le récit des Fastes ${ }^{28}$.

En somme, tout se passe comme si Ovide avait glané dans l'Énéide, avec une attention minutieuse et une grande lucidité, les jalons d'une histoire ultérieure, non sans prendre soin d'insérer ici et là des réminiscences du texte même. Son projet se dessine alors : construire un récit annexe en interaction permanente avec l'épopée virgilienne, grâce à la capture et au détournement de multiples motifs. À cette fin, Ovide extrait Anna d'un univers diégétique où elle n'avait qu'un rôle d'appoint : introduite pour les besoins passagers du drame qui se jouait dans le livre IV, elle était ensuite oubliée par le récit virgilien ${ }^{29}$. Elle reçoit dans les Fastes une fonction inédite, qui la transpose en un double féminin d'Énée ${ }^{30}$.

19 Ce faisant, l'entreprise d'Ovide s'inscrit dans la perspective d'une continuation, qui va jouer à la fois sur une période rétrospective par rapport à la diégèse de l'Énéide, en relatant le sort de Carthage aussitôt après la mort de Didon, mais aussi prospective, en évoquant le devenir d'Énée, bien au-delà de son duel victorieux avec Turnus. Selon la terminologie mise au point par Gérard Genette, on peut donc attribuer à l'histoire d'Anna dans les Fastes une double dimension, analeptique et proleptique ${ }^{31}$. Mais ce qui la caractérise avant tout, c'est le recours à des éléments narratifs que l'œuvre antérieure avait laissés en suspens : à cet égard, elle relève d'une dimension paraleptique ${ }^{32}$. Gérard Genette mentionne, comme exemples d'une telle démarche, les Nostoï d'Hégias qui, en 
regard de l'Odyssée,narraient les aventures des autres chefs grecs à leur retour de Troie. Cependant lorsqu'Ovide retient en tant que personnage principal non un guerrier mais une femme, un inévitable décentrement de l'action en résulte, puisque celle-ci ne peut se fonder sur les ressorts habituels de l'héroïsme épique.

Ce n'est donc pas un hasard si le poète des Fastes introduit son récit par une référence massive à l'une de ses œuvres, faisant ainsi reposer la continuation sur une base dédoublée : il s'agit de la septième Héroïde, lettre fictive écrite à Énée par Didon, juste avant son suicide ${ }^{33}$. Or les derniers vers comportent précisément une invocation pour Anna, Didon exprimant l'espoir que celle-ci veillera sur ses cendres. Et la reine termine en composant sa propre épitaphe, dont le texte exact, désormais inscrit sur le marbre de son tombeau, est repris dans les Fastes, signalant de la sorte une claire filiation $(H$. VII, 195-196 = F. III, 549-550) ${ }^{34}$. D'emblée, par ce rappel qui donne l'impulsion au récit, se manifeste une piste concurrente à celle de l'épopée ${ }^{35}$.

21 Mais l'évidence de la greffe opérée à partir d'un texte élégiaque antérieur ne doit pas captiver la lecture au point de masquer la complexité de la démarche ovidienne. En effet, dès l'amorce de l'épisode, elle se combine avec un affleurement de références à l' Énéide.

22 Ainsi, le jeu sur le verbe arserat, répété à l'initiale des deux premiers vers et signifiant tour à tour "brûler d'amour" puis "être incinéré", offre un rappel en abrégé de la correspondance établie par Virgile entre la flamme métaphorique évoquant à plusieurs reprises, au début de livre IV, l'amour éprouvé par Didon, et le feu du bûcher qui, à la fin, va consumer le cadavre de la reine ${ }^{36}$ : cette issue est rapidement évoquée, à l'amorce du livre V, lorsqu'Énée, depuis son navire, distingue la lueur des flammes sans en deviner la cause.

23 Ainsi, les vers suivants, dans le récit des Fastes, laissent discerner des échos ponctuels au livre IV de l'Énéide, qui se mêlent étroitement avec le rappel flagrant de la septième Héroïde $^{37}$. Or tous proviennent des ultimes paroles qu'émet Anna devant sa sœur mourante. En effet exstructis in sua fata rogis ("sur le bûcher dressé pour l'accomplissement de son destin", F. III, 546) répond, chez Virgile, à l'instant où la sœur de Didon saisit enfin le rôle qu'elle a joué en accomplissant les préparatifs demandés par la reine et en élevant pour elle un bûcher : his etiam struxi manibus ("c'est même de mes mains que je l'ai dressé", En. IV, 680) ${ }^{38}$. Davantage, la corrélation flagrante du distique suivant (F. III, 547-548) avec H. VII, 194 s'accompagne d'une variation notable, l'ajout du participe moriens, tiré du même passage virgilien, où Anna déplore que Didon, "en mourant", n'ait pas voulu d'elle comme compagne (En. IV, 678) ${ }^{39}$.

C'est donc un entrelacs de résonances qui se dispose, montrant que, si le démarrage du récit est ouvertement fondé sur les derniers vers de la septième Héroïde, il s'appuie conjointement surle livre IV de l'épopée ${ }^{40}$. Une telle amorce laisse présumer que les voyages racontés ensuite pourraient être envisagés comme la métaphore d'un parcours intertextuel ${ }^{41}$. En tout cas, avec des modèles aussi différents que l'Énéide et les Héroïdes, s'annonce un mixage, conduisant à l'hybridation des genres poétiques. De fait, Ovide met à l'épreuve le scénario de l'errance épique dans une œuvre qui, en son principe, ne s'y prêtait guère, ni par sa versification élégiaque, ni par sa découpe en brefs récits voués à l'étiologie. Cette intégration des malheurs d'Anna dans un contexte de liesse populaire, avec lequel ils tranchent, suppose à la fois référence et distance par rapport aux normes requises. Un tel dédoublement va orienter le jeu entre un parallélisme 
insistant avec les aventures d'Énée, quant à la trajectoire globale du récit, et une démarcation notable, quant aux circonstances de chaque étape.

\section{3- Un cheminement sur les traces d'Énée}

Quand il imagine les aventures d'Anna, Ovide échafaude la diégèse de telle façon que la plupart des événements comportent quelque analogie avec un épisode au moins dans l' Énéide. Tout en suivant ce principe, il réussit la gageure de transposer en abrégé le déroulement de son modèle ${ }^{42}$. Pour ce faire, il ne se borne pas à disséminer dans le récit des indications qui établissent des rapprochements avec le scénario virgilien, mais il ménage une structure d'ensemble conforme à celle de l'épopée. En effet l'histoire se répartit entre deux volets qui évoquent successivement le périple du personnage puis son installation conflictuelle dans le Latium ; les développements consacrés à chacune de ces phases ont une longueur presque identique, reprenant ainsi, bien qu'à une tout autre échelle, la découpe de l'Énéide en deux groupes de six livres ${ }^{43}$.

Parallèlement, Ovide a pris soin d'attribuer une durée comparable à la diégèse, en chiffrant à deux reprises le temps écoulé : Anna, qui est demeurée trois années dans Carthage conquise avant de se résoudre à l'exil (v. 557-558), séjourne deux ans chez le roi Battus (v. 575-576); Énée, quant à lui, avait erré sept ans sur les mers (En. I, 755-756) ${ }^{44}$.

Force est d'admettre que cette chronologie soulève une difficulté: elle est en discordance avec la prophétie de Jupiter annonçant la mort du héros, trois années seulement après son installation en Italie (En. I, 265-266); il serait donc impossible que, dans les Fastes, Anna, lorsqu'après son naufrage elle erre près de Lavinium, le rencontre ${ }^{45}$. En fait, on découvre chez Denys d'Halicarnasse des indications qui, pour ce qui concerne le séjour d'Énée en Italie, s'accordent avec la version des Fastes : le héros, après avoir fondé Lavinium et avoir épousé Lavinia, succède au roi Latinus deux ans après son arrivée (Ant. Rom. I, 64, 1) ; et c'est au bout de trois années de règne qu'il meurt au combat (Ant. Rom. I, 64, 3). Cependant, chez l'historien grec, le périple d'Énée, qui a duré beaucoup moins longtemps, ne comporte pas d'étape à Carthage.

Ovide, qu'il ait eu un accès direct à cette version ou qu'il ait été au courant d'une tradition analogue, semble donc avoir fusionné deux scénarios inconciliables à propos d'Énée. On serait tenté de supposer que, de la sorte, il s'est plu à projeter un éclairage humoristique sur le désordre de la tradition légendaire ${ }^{46}$. Un indice textuel le confirme : curieusement, la disposition des v. 557-558 rappelle celle de la prédiction jupitérienne chez Virgile (En. I, 265-266 $)^{47}$ : cela revient à en intégrer une trace discrète, au moment même où commence à en être contredite la réalisation ${ }^{48}$. Certes, mettre ainsi en cause la justesse d'une prédiction intégrée à l'épopée n'allait pas sans introduire une distance envers les valeurs religieuses qui se rattachaient au destin du héros ${ }^{49}$.

Il n'empêche que, dans les deux récits, l'échelonnement de l'action répond à un même schéma : de Carthage au Latium, un couple d'étapes intermédiaires ponctue le parcours d'Anna tout comme celui d'Énée chez Virgile. Elle s'arrête à Malte, puis aborde à peine le sud de l'Italie, d'où elle est aussitôt chassée par la tempête ; de même, le héros, après avoir quitté Didon, fait halte en Sicile, où il célèbre des jeux en l'honneur d'Anchise, et séjourne ensuite en Campanie, pour découvrir, guidé par la Sibylle, le séjour des morts. Mais l'exil du chef troyen l'avait préalablement mené de Troie à Carthage, ses voyages 
étant ainsi redoublés. Dès lors Ovide, s'appuyant sur le retour de certaines circonstances dans l'Énéide, adopte à plusieurs reprises, au long de son récit, un procédé de corrélation couplée, en tramant des rapports avec deux épisodes assimilables chez Virgile. En fait, c'est avec la première navigation d'Énée que le cheminement d'Anna présente les correspondances les plus suivies, souvent accompagnées d'échos, notables ou diffus ${ }^{50}$.

Il va de soi qu'une même sorte d'événement fournit un commun moteur à l'action : la chute d'une ville prise par les ennemis occasionne la fuite. Cependant une particularité plus ténue associe le moment du départ : la présence subliminale de Didon, pressentie par Anna, recoupe l'apparition de Créüse à Énée. Ovide prête à son héroïne envers les cendres de sa sœur une attitude qui rappelle celle du chef troyen envers l'ombre de son épouse : même effort pour serrer contre soi un être qui se dérobe, même cri d'adieu ${ }^{51}$.

Dans cette amorce du récit ovidien, on découvre la répétition d'un motif : à faible distance, la mention redoublée du regard plein de nostalgie que porte Anna aux remparts de sa sœur ${ }^{52}$. Alors même que la réécriture s'applique à restreindre l'ampleur de son modèle, ce redoublement pourrait sembler d'une prolixité superfétatoire. Mais l'itération est apte à prendre la valeur d'un signal, dans la mesure où elle autorise une référence échelonnée aux deux appareillages majeurs de l'Énéide, quand le héros abandonne Troie, puis Carthage. De fait, le flux des recoupements textuels évoque tour à tour ces départs : d'abord, le second hémistiche du v. 559, lacrimansque sororia linquit [moenia] ("en pleurant, elle quitte les remparts construits par sa sœur") établit une relation avec les larmes que verse le Troyen en s'éloignant de sa patrie, litora cum patriae lacrimans portusque relinquo ("quand, en pleurant, je quitte le rivage de ma patrie et le port", En. III, 10) ${ }^{53}$; ensuite, le premier hémistiche du v. 566, moenia respiciens, reprend exactement celui d'En. V, 3, évoquant l'ultime regard d'Énée sur les murailles de Carthage ${ }^{54}$.

De la sorte, cette réécriture combinatoire promeut des réminiscences qui tendent à établir une identification d'Anna avec Énée. Sa mise en œuvre se poursuit lors de l'étape à l'île de Malte ${ }^{55}$ : si l'accueil de Battus fait songer à celui des Troyens par Didon chez Virgile, il évoque non moins, durant leur voyage initial, les haltes dans des îles, à Délos puis en Crète $^{56}$. En effet, de même que la reine de Carthage propose aux Troyens sa ville comme séjour (En. I, 573), le souverain de Malte offre à l'exilée de partager sa terre (F. III, 572) ${ }^{57}$. Mais l'homologie de scénario se marque davantage avec les deux îles abordées précédemment par Énée : dans la première il est reçu par un roi hospitalier, dans la seconde il trouve, avant que la peste l'oblige à repartir, une installation qui, ainsi que pour Anna, tant que Pygmalion ne la menaçait pas, promettait d'être durable.

Pendant son trajet ultérieur, Anna, alors qu'elle touche le sud de l'Italie, subit une terrible tempête, conformément à un motif notoire des voyages épiques. La circonstance répond à l'ouragan qui, au début de l'Énéide, au moment où les Troyens quittaient la Sicile pour l'Italie, emporte leurs navires vers Carthage ${ }^{58}$. Mais Ovide, fidèle à sa démarche de réécriture combinée, ménage une connexion avec l'autre tempête dont les vaisseaux d'Énée, en quittant la Crète, ont été victimes au milieu de ténèbres. Jouant sur les décalages, il choisit un moment de répit dans l'action pour introduire un net écho: un début d'hexamètre commun avec Virgile évoque les voiles que l'on amène, uela cadunt (En. III, 207 et $F$. III, 585) ${ }^{59}$. Ce faisant, le poète inverse la place du motif dans le cours de la diégèse : alors que l'instant de calme, chez Virgile, 
marquait le retour final à un temps serein, il précède, pour Anna, un brusque déchaînement des flots ${ }^{60}$.

Ainsi l'héroïne, à la différence des Troyens, dont le destin promet de finalement couronner les luttes, semble vouée à des catastrophes imprévisibles et sans issue. De fait, après un naufrage, qui la laisse pourtant saine et sauve, quand elle atteint, comme Énée, le Latium, sa rencontre avec le chef troyen devenu roi occasionne pour elle une ultime épreuve ${ }^{61}$. Jusque ici, le jeu de la réécriture, notamment parce qu'il ménageait une continuité dans les relations avec le livre III de l'Énéide, offrait la piste d'une assimilation entre Anna et le héros virgilien ${ }^{62}$. Lorsque les deux personnages se rejoignent, leur confrontation ouvre un terrain nouveau pour le développement de correspondances textuelles.

Cependant la mise en œuvre d'un registre dédoublé continue de guider la démarche ovidienne, qui mobilise surtout les analogies avec l'arrivée d'Énée à Carthage, mais rappelle conjointement, même si la ressemblance est discrète, l'accueil du roi Latinus ${ }^{63}$. Ainsi, lorsqu'Énée découvre Anna, la question qu'il se pose sur les motifs de sa venue en Italie est dans l'esprit de celles qu'adressait le père de Lavinia aux Troyens (F. III, 606 et En. VII, 197-198) ${ }^{64}$. Par contre, l'ensemble de la scène découle du livre I de l'Énéide, quand le héros explorait la contrée où les flots l'avaient jeté : "il marche, accompagné du seul Achate" (...uno graditur comitatus Achate, v. 312) ; il croisait alors sa propre mère, Vénus qui, déguisée en chasseresse, demandait aux deux hommes s'ils n'avaient pas vu, égarée dans la forêt, l'une de ses sœurs (v. 322). Chez Ovide la fin du v. 603 intègre un manifeste écho, précisant qu'Énée chemine "accompagné seulement d'Achate" (...solo comitatus Achate) ; aussitôt après, le Troyen reconnaît la sœur de Didon, perdue, à la suite de son naufrage, sur des côtes inconnues ${ }^{65}$.

Mais la correspondance s'avère plus complexe : on s'avise que, dans les Fastes, ce regard jeté par Énée rappelle de façon plus nette encore le moment, chez Virgile, où le héros, juste rescapé des flots, "aperçoit sur le rivage trois cerfs errants" (...tris litore ceruos / prospicit errantis..., En. I, 184-185). En effet, le début du second vers est repris par celui du v. 605, avec une variation du préfixe pour le verbe initial, le rapprochement étant renforcé, dans le v. 603, par l'ablatif litore ${ }^{66}$. Dès lors, par ce jeu d'échos multiples, Anna, dans sa rencontre avec Énée, s'identifie au moins autant à un gibier qu'à une chasseresse $^{67}$ : elle semble ainsi potentiellement vouée, selon une sorte d'annonce en filigrane, à être la victime de celui qui, pourtant, assume à son égard une bienveillante hospitalité, analogue à l'attitude qu'avaient adoptée envers lui, chez Virgile, Didon puis Latinus $^{68}$.

Logiquement, la nouvelle arrivante suscite en lui le souvenir ému de sa sœur. C'est pourquoi il évoque sa dernière entrevue avec l'ombre de Didon, lorsqu'il est descendu aux Enfers. Or la manière dont il interpelle Anna, les serments qu'il prononce, recoupent le début du plaidoyer grâce auquel, dans l'Énéide, il tâchait d'apaiser l'ombre hostile de la défunte (F. III, 613-615 et En. VI, 458-459) ${ }^{69}$. Une telle similitude, comme elle associe métonymiquement les malheurs de Didon à la figure d'Anna, laisse prévoir pour celle-ci un destin comparable ${ }^{70}$.

38 Ainsi, en référence à l'épopée virgilienne, le statut analogique du personnage se dédouble : aux parallélismes de son voyage avec celui d'Énée, s'ajoutent désormais les rapprochements avec sa sœur. Corrélativement, le chef troyen manifeste envers Anna sa générosité en lui prodiguant les cadeaux, comme un rappel des présents offerts à 
Didon dans l'Énéide. Mais sa munificence aboutit à un résultat néfaste, en confortant la méfiance de Lavinia (F. III, 635-636) ${ }^{71}$.

Cette dernière reçoit dans le scénario ovidien une place décisive et son personnage prend un relief qu'il n'avait nullement chez Virgile. Loin d'être la timide et discrète jeune fille de l'épopée, elle agit avec une haine résolue, tout en dissimulant son animosité $^{72}$. Son attitude envers Anna renvoie, elle aussi, à une double origine : elle ne ressemble pas seulement aux rancœurs de Didon abandonnée, mais tient aussi de l'agressivité que, dans l'épopée, la furie Allecto inspirait contre Énée à Turnus et Amata $^{73}$. Comme l'épouse de Latinus, loin d'être soumise aux injonctions de son mari, elle suit son désir de vindicte, sans même craindre la mort.

Le dénouement de l'histoire intègre un motif marqué, tout comme la tempête, du sceau épique, l'apparition d'une ombre salvatrice, et l'influence virgilienne s'y manifeste avec un singulier relief. En effet, quand Anna voit dans son sommeil l'ombre de Didon, la scène rappelle notamment, la concentrant sur quelques vers, celle où le spectre d'Hector visite Énée endormi ${ }^{74}$. Les deux passages suivent le même ordre : une fois évoquées les circonstances de la vision nocturne (En. II, 268, 271 et $F$. III, 639), l'accent mis sur les traces laissées par une mort violente est suivi d'un appel à fuir (En. II, 289 et F. III, 641) ${ }^{75}$. C'est le second point qui offre l'analogie la plus frappante, d'autant qu'il rejoue la dimension pathétique de l'épopée : dans un pentamètre, dont les termes sont transposés d'un hexamètre virgilien, Ovide rapporte à la chevelure de Didon le participe squalens qui concernait la barbe en désordre d'Hector; il accentue l'effet d'hypotypose en recourant, pour évoquer les taches de sang, au long adjectif sanguinulenta ${ }^{76}$ :

squalenti Dido sanguinulenta coma (F. III, 640)

"Didon, couverte de sang, la chevelure souillée"

squalentem barbam et concretos sanguine crinis (En. II, 277)

"la barbe souillée, les cheveux collés par le sang"

Cette scène, en renvoyant ainsi aux heures qui ont précédé la chute de Troie, est pour Ovide l'occasion d'un frappant retour en arrière dans l'Énéide. De la sorte, outrepassant la linéarité narrative, suivant laquelle le récit des Fastes, dans son déroulement même, se trouve associé au modèle virgilien par maintes circonstances analogues, puis, lors des retrouvailles d'Anna avec Énée, finit par en prolonger la diégèse, c'est une circularité qui découle cette fois du rapport entre les textes, suggérant que les péripéties de la légende s'inscrivent dans un continuel recommencement, lié au jeu de la réécriture ${ }^{77}$.

42 Pour autant, les corrélations entre l'Énéide et les aventures d'Anna ne s'arrêtent pas là, mais s'étendent jusqu'au rapt de l'héroïne par le Numicius ainsi qu'à sa métamorphose. Comme cette disparition surnaturelle ne cadre guère avec un dénouement épique, la stratégie assimilatrice fait appel à une série d'échos issus d'un contexte bien distinct. En effet l'évocation du cours d'eau renvoie au passage où le Tibre, chez Virgile, après être apparu en songe à Énée, en lui enjoignant d'aller chez le roi Évandre, apaise ses flots pour faciliter la navigation des Troyens vers Pallantée $e^{78}$.

Cette correspondance, fondée sur un motif aquatique, manifeste un décalage entre l'action du héros soutenu par un dieu et la passivité d'Anna dérobée à sa propre existence $^{79}$. En même temps, elle offre un signal implicite de l'analogie entre l'issue qu'Ovide a réservée à son personnage et l'ultime destin qu'attribuait à Énée la tradition légendaire : un rapport métonymique s'établit avec l'apothéose du héros, disparu lui 
aussi dans le Numicius, événement qui ne figurait pas dans l'Énéide, mais qui était raconté dans les Métamorphoses ${ }^{80}$. Ovide capte ainsi plusieurs détails de la fiction virgilienne pour en faire comme les jalons d'un devenir potentiel ${ }^{81}$. On a là un subtil accord final dans la délicate orchestration des similitudes avec le modèle ${ }^{82}$.

En somme, au-delà des rapports à l'histoire proposée par l'Énéide, qu'évoque massivement et prolonge le récit intégré dans les Fastes, la démarche d'Ovide atteste une exploration des virtualités, qui puise, selon une formule de Stephen Hinds, aux "racines mêmes de la poésie de Virgile"83. Certes, l'afflux des corrélations ne saurait faire oublier les nombreux aspects qui différencient radicalement les aventures d'Anna et la geste d'Énée. Au contraire, c'est grâce au jeu des ressemblances, invitant à des comparaisons, que se laisse d'autant mieux appréhender la distance par rapport à certains traits essentiels de l'épopée. De fait, la récurrence des échos virgiliens est sans cesse confrontée à la remise en cause de l'univers héroïque.

\section{4- Les distances prises envers l'épopée}

La foncière contestation induite par l'entreprise ovidienne dans le cadre du genre épique a pour base une alliance conflictuelle : un scénario façonné à partir de l'épopée, prend comme personnage principal une femme, incapable de lutter contre les aléas du sort. Le récit à narrateur hétérodiégétique exclut l'approche qui était celle des Héroïdes, où le point de vue subjectif de l'énonciatrice permettait d'harmoniser l'évocation de telles circonstances avec la tonalité de l'élégie. C'est donc, en prenant l'Énéide pour toile de fond, la mise en œuvre de tensions représentatives qu'assume le poète, d'autant plus nettement que, dans le préambule, il en annonce sur un mode allusif le principe.

En effet, pour décrire les huttes éphémères que fabriquent les participants aux réjouissances en l'honneur d'Anna Perenna, est employée une formule qui rappelle singulièrement un énoncé bien connu de Vitruve, s'insurgeant contre l'invraisemblance des architectures graciles dont les peintres de son époque se plaisaient à enjoliver les décors muraux des maisons romaines. Dès que l'on rapproche les passages, saute aux yeux un recoupement qui, semble-t-il, n'a pas été signalé jusqu'à présent (De architectura, VII, 5, 3 et $F$. III, 529-530) ${ }^{84}$ :

Pro columnis enim statuuntur calami, pro fastigiis appagineculi striati cum crispis foliis et uolutis...85

"En effet, au lieu de colonnes, on dresse des roseaux; au lieu de frontons, des fioritures avec des feuilles enroulées et des volutes..."

pars ubi pro rigidis calamos statuere columnis, desuper extentas imposuere togas.

"certains, après avoir dressé, au lieu de fermes colonnes, des roseaux, ont disposé au-dessus leurs toges déployées."

Associé dans les Fastes à une atmosphère d'euphorie, un tel écho sous-entend une remise en cause du jugement vitruvien, une valorisation de l'esthétique ainsi rappelée. À l'inverse, l'adjectif rigidus, appliqué aux véritables colonnes, et qui ne figurait pas chez Vitruve, est propre à connoter une roideur caractérisant la structure des édifices publics $^{86}$. Cette approche leur oppose implicitement la souplesse et l'inventivité, incarnées par les adeptes d'Anna Perenna : avec humour, Ovide renchérit sur l'absence de frontons, en les remplaçant par de simples tissus ${ }^{87}$. 

procurant au héros, notamment à Énée, une connaissance graduelle du futur grâce à une série d'annonces divinatoires, les tribulations d'Anna en sont absolument dénuées ${ }^{92}$. Privée de toute révélation, qui lui enseignerait les voies du destin, la sœur de Didon est livrée à son humanité défaillante ${ }^{93}$. Et dans cet univers fictionnel, à l'opposite de la tradition épique, les dieux ne se manifestent pas : jamais le récit n'évoque leur intervention favorable ou adverse, pas même lorsque se déchaîne l'ouragan. Ovide, à cet égard, s'éloigne résolument de l'Énéide, où, dès la tempête initiale, les immortels sont omniprésents, où leurs débats ponctuent les événements terrestres et leur donnent sens ${ }^{94}$. 
53 Ainsi les étapes du voyage, loin de correspondre à une avancée du personnage sur un parcours, certes semé de dangers, mais conduisant vers un but attendu, se succèdent comme les maillons d'une chaîne factuelle contingente, dont l'issue reste indéterminée. En somme, c'est la téléologie propre à la diégèse épique, fondée sur l'accomplissement nécessaire des fata, de la destinée, qui est récusée. Le déroulement du périple, au lieu d'être motivé par un aval que prédispose la tradition légendaire, se trouve déterminé par l'amont d'un modèle textuel, ainsi que par une logique de transposition qui, en quelque sorte, sécularise le schéma épique, lui retire ses implications glorieuses et transcendantes. C'est pourquoi la série des épreuves ne confère nul prestige à l'héroïne, mais se produit comme un cumul de malchances et de persécutions. À cette constante répond l'emploi d'un leitmotiv, propre à unifier les aventures d'Anna, celui d'une fuite perpétuelle ${ }^{95}$.

54 En somme, presque tous les traits qui caractérisent le voyage épique sont absents. Mais cela n'interdit pas que subsiste une indéniable référence au genre. C'est qu'Ovide, en retenant pour la diégèse un schéma analogue à celui de l'Énéide, en multipliant les réminiscences et en introduisant des motifs caractéristiques, établit comme une synecdoque d'épicité, où des repères isolés projettent un effet d'ensemble. Sur cette base, le poète peut jouer d'une apparente désinvolture, qui met en scène la distance prise par rapport au genre. Les bizarreries que cela entraîne dans le récit ne sauraient donc être ramenées à une conséquence mécanique de l'abrègement radical qu'exige la physionomie des Fastes par rapport à l'ampleur de l'épopée, mais elles se conçoivent dans le cadre d'une démarche originale, où le recours à la stylisation s'accompagne d'un éclairage humoristique voire ironique sur les événements racontés.

55 En particulier, le retranchement de motivations narratives et l'émergence de paradoxes représentatifs exhibent l'arbitraire des situations fictives qui se succèdent, alors que, d'habitude, les récits épiques, notamment lorsqu'ils invoquent les nécessités du destin et la volonté des dieux, tendent à l'estomper.

56 C'est ainsi que, sans nulle explication, est brusquement procuré à l'hérö̈ne ovidienne, muni des compagnons nécessaires, un unique navire, répondant à la fabrication d'une flotte par Énée : la circonstance est indiquée par les offices du seul participe nancta ("ayant trouvé", v. 565) ${ }^{96}$. Au moment où l'histoire s'engage sur les traces de son modèle, les détails de son déroulement ne semblent pas devoir être justifiés.

57 C'est ainsi que, dans le scénario de la tempête, s'introduisent deux étrangetés successives, qui inversent le rôle dévolu à ce type d'épisode, notamment dans le déroulement $\mathrm{du}$ récit virgilien ${ }^{97}$. D'une part, au lieu d'empêcher le personnage d'atteindre le terme de son périple, la tornade l'y conduit justement ${ }^{98}$; il est vrai qu'Anna elle-même n'a pas conscience d'être arrivée à destination, puisque le sort ne lui assignait aucun objectif. D'autre part, au lieu de relâcher sa violence, en laissant le personnage gagner la côte, la tourmente finit par faire sombrer le bateau; il est vrai que cette catastrophe elle-même comporte une issue insolite, puisque l'ensemble des passagers est déposé indemne sur le rivage (v. 599-600) :

Ducitur ad Laurens ingenti flamine litus, puppis et expositis omnibus hausta perit.

"Sur le rivage laurente, une formidable rafale entraîne le navire; tout le monde étant débarqué, il périt, englouti." 

rôle de second ordre. Et c'est une pâle image qu'il dessine, telle que la résume Carole Newlands : "Énée apparaît comme un héros insipide, incapable, marié à une mégère jalouse" ${ }^{102}$. Cependant le récit accorde au chef troyen une place suffisante pour faire ressortir, par une série d'indications contrastées, les décalages avec sa figure dans l' Énéide. Si l'essentiel du discours direct lui est réservé, ses paroles sont dénuées de portée, lorsqu'il proclame rétrospectivement son innocence envers Didon comme lorsqu'il adjure inutilement Lavinia de faire bon accueil à l'exilée. Si le poète prend soin de le désigner d'emblée, selon une formule typiquement virgilienne, comme "le pieux Énée" (pius Aeneas, v. 601) ${ }^{103}$, ses mérites comme guerrier sont en même temps escamotés : il n'est pas question de sa lutte contre les Rutules et Turnus, comme s'il lui avait suffi d'épouser la fille de Latinus pour devenir roi (v. 601-602) ${ }^{104}$.

présentation du personnage, en regard de l'épopée virgilienne, est susceptible de mettre en lumière une particularité de celle-ci : lorsqu'Ovide souligne que l'arrivée d'Anna réveille dans l'esprit d'énée l'émouvant souvenir de Didon (v. 612), il suggère avec humour que la défunte a pu être oubliée fort longtemps par le héros. De fait, dans les six derniers livres de l'Énéide, il n'est jamais directement question d'elle ${ }^{105}$. Dès lors, on est porté à sourire, quand l'hôte d'Anna affirme combien est vive sa mémoire des 
bienfaits reçus à Carthage puis, s'adressant à Lavinia, se prétend animé, en recueillant l'exilée, d'une pieuse gratitude (v. 623 et 629) ${ }^{106}$.

63 Au-delà de cette implicite mauvaise foi, c'est par ses actes mêmes qu'Énée se trouve dévalorisé. L'autorité qu'il affiche devant son épouse, quand il lui recommande Anna, s'avère illusoire et sa démarche a des conséquences catastrophiques. En effet, lorsqu'il adjure Lavinia de chérir la nouvelle venue comme une sœur, par ce terme, évoquant inévitablement Didon, il associe Anna et ses amours passées ${ }^{107}$. Même sans retenir l'hypothèse très débattue d'une référence allusive à une version légendaire assignant au héros une liaison effective avec Anna, on peut concevoir que la jalousie envahisse Lavinia $^{108}$ : les propos d'Énée entraînent son épouse à identifier la voyageuse comme capable de remplacer Didon et de ranimer une passion enfouie, donc à voir en elle une rivale potentielle ${ }^{109}$. Ainsi, par la maladresse qu'Ovide lui attribue, le héros de Virgile devient le responsable d'un désastre domestique. Incapable de se faire obéir et de remplir sa fonction d'hôte, il est privé de tout prestige. C'est alors que le récit le met hors-jeu, aussi brusquement qu'il l'avait fait avec le navire d'Anna. Ainsi est refermée une sorte de parenthèse, qui ne donnait une place décisive à Énée que pour mieux le disqualifier, tandis que l'épisode se recentre sur le personnage principal.

Cette ultime réorientation, éliminant le héros virgilien, a une valeur symptomatique : l'héroïne ovidienne reste sans défense ni perspective, exposée à la haine de Lavinia, qui résulte paradoxalement de l'intervention d'Énée en sa faveur. Une telle circonstance, où l'aide prodiguée se mue en son opposé, témoigne d'une complexité dans la redistribution des rôles par rapport à l'Énéide ${ }^{110}$. Anna, qui occupait la fonction d'adjuvant, accède à celle de sujet dans les Fastes, alors qu'Énée, quand il apporte son soutien à l'exilée, est soumis à l'échange inverse ${ }^{111}$. Mais Ovide ne se borne pas à permuter les actants issus de l'épopée virgilienne : il trouve dans l'Énéide la piste d'un retournement interne. Anna y exerçait déjà une action ambiguë, Didon recevant d'elle une aide qui se révélait concourir à sa destruction; corrélativement, l'apparent auxiliaire, que représente dans les Fastes le héros virgilien rétrogradé, provoque à son insu la perte d'Anna. Au-delà, pour la voyageuse elle-même, qui semble promue dans les Fastes au rôle de sujet, s'opère une mutation radicale : à la différence du héros épique, aucun but n'est assigné par les destins à son périple, aucun objet autre que la simple sauvegarde de sa vie ${ }^{112}$. C'est pourquoi, elle ne saurait fournir, dans une diégèse renouvelée, un authentique équivalent d'Énée, mais, en cohérence avec le rabaissement $\mathrm{du}$ héros troyen et la sécularisation de l'histoire virgilienne, elle n'assume le rôle de sujet que sur un mode mineur, selon un retrait calculé.

On assiste donc, à travers la reprise organisée du schéma emprunté à l'Énéide, à une déconstruction en règle du modèle fictionnel et de ses implications glorifiantes ${ }^{113}$. À cet égard, l'issue est révélatrice, comme une ultime étape dans le parcours de l'héroïne : soudain, avec l'apparition de Didon et de l'unique dieu agissant dans l'histoire, le Numicius, la composante surnaturelle reprend ses droits ; mais la dimension légendaire intervient elle aussi de manière décalée, aboutissant à une métamorphose qui dérobe l'héroïne à elle-même plutôt qu'elle ne la consacre comme telle. De plus les événements se déroulent sur un fond de réminiscences élégiaques, dont la venue, loin d'être anodine, se répercute sur la portée de l'histoire. Examiner une telle intrication va aider à préciser les rapports entre la dynamique fictionnelle de l'épisode, le recours au modèle virgilien et un questionnement distancié sur la mise en œuvre des genres poétiques. 


\section{5- Les bifurcations vers l'élégie}

La singularité du rôle assumé par Anna se manifeste dans la physionomie déceptive que revêtent ses aventures, dénuées de tout contrecoup prestigieux qui, au-delà des simples péripéties, leur donnerait sens. Ce manque d'un objet actantiel valorisé a pour corrélat une itérative mise en œuvre d'auxiliaires déficients à divers titres, qui ne secourent l'héroïne que pour l'abandonner aussitôt à une nouvelle épreuve ${ }^{114}$. Le roi Battus, qui l'accueille, incarne l'antithèse du guerrier, lorsque, devant les menaces de Pygmalion, il se refuse absolument à la lutte et renvoie l'exilée à ses errances ${ }^{115}$. Énée, qui s'affirme son protecteur, ignorant quels dangers pèsent sur elle, lors même qu'il l'y a exposée, est par conséquent incapable d'assumer sa fonction et s'absente du récit. L'ombre de Didon, qui avertit Anna et lui permet d'échapper au complot ourdi par Lavinia, la lance dans une fuite éperdue, où elle va effectivement se perdre ${ }^{116}$.

De fait, l'accès à un ultime refuge coïncide avec la violence d'un rapt; et si Anna trouve un abri dans les eaux du Numicius, c'est par l'abolition de son autonomie comme personnage (v. 647-648) ${ }^{117}$. La préservation d'Anna, ainsi que le souligne Parshia LeeStecum, se révèle donc hautement problématique ${ }^{118}$. Loin d'accéder, comme Énée, à un séjour promis par les destins, elle est emportée de catastrophe en catastrophe jusqu'à une fausse issue, une impasse, où elle est doublement dépossédée d'elle-même: d'abord, enlevée par le dieu et devenant ainsi l'objet d'un désir, elle perd son statut d'héroïne ; puis, subissant une métamorphose concomitante, elle est, en définitive, soustraite à son identité même ${ }^{119}$.

8 En somme, le retour spectral de Didon, lors même qu'il présente une forte coloration épique, à cause notamment des similitudes avec l'apparition d'Hector dans l'Énéide, entraîne Anna hors de la sphère narrative qui caractérise l'épopée. Car la rencontre finale avec le surnaturel relève d'une logique extérieure à ce genre : le rapt et métamorphose, loin de se rattacher à la catégorie des épreuves qualifiant le héros, en constituent la négation. Du reste, la fin du récit, tout en s'appuyant, on l'a vu, sur une scène de l'Énéide, le secours apporté aux Troyens par le Tibre, baigne dans une ambiance très décalée par rapport à un dénouement épique : l'accent mis sur le calme du Numicius, qui permet les révélations d'Anna transformée en nymphe, et sur l'euphorie des témoins, qui, partis à sa recherche, peuvent à présent festoyer, tranche avec les moments conclusifs du récit épique, d'ordinaire marqués par la violence et la mort $^{120}$. En somme, jusqu'à leur terme, les aventures d'Anna présentent une interaction incessante de similitudes et de contrastes vis-à-vis de l'Énéide.

Prise dans son ensemble, la diégèse ovidienne intègre une succession de périls comparables aux épreuves du modèle épique, mais loin de parcourir une courbe ascendante, comme celle qui instaure à mesure un héros, elle suit un développement stochastique, selon une série de soubresauts fortuits, assimilables sous cet angle aux accidents de la passion qu'égrènent les pièces d'un recueil élégiaque.

Si, dès lors, fait défaut l'emprise d'un destin qui assignerait à son déroulement une finalité supérieure, l'épisode reçoit une cohérence d'un autre ordre, la mise en place d'une architecture reliant les bornes du récit. Cet agencement, autonome par rapport à l'œuvre de Virgile et propre à unifier le texte, s'accomplit sous les auspices de l'élégie. En effet, avant même le départ d'Anna, la cérémonie pour honorer les cendres de Didon prédispose la scène où lui apparaîtra en rêve l'ombre de la reine ${ }^{121}$. Or cette célébration, 
liée au souvenir de la défunte, entretient d'étroits rapports avec la septième Héroïde ${ }^{122}$. Cette incidence du contexte élégiaque se retrouve justement dans la dernière étape du récit, où de multiples échos à d'autres œuvres ponctuent l'apparition de Didon mais aussi la fuite et la transfiguration d'Anna.

De fait, pour évoquer l'ombre de la reine, Ovide combine les réminiscences de l'Énéide et de Tibulle (II, 6, 37-40) ${ }^{123}$. Puis, quand Anna, bouleversée par la mise en garde de sa sœur, fuit sans perdre un instant, une formule décrivant la légèreté de sa tenue attire l'attention: tunica uelata recincta ("enveloppée d'une tunique flottante", v. 645). Cet hémistiche est emprunté aux Amours (I, 5, 9), où il connote l'érotique tournure de Corinne, qui vient rejoindre le poète dans sa chambre ${ }^{124}$. Au passage, le narrateur des Fastes justifie qu'Anna ait trouvé la force de s'aventurer au dehors en pleine nuit: audacem fecerat ipse timor ("la crainte à elle seule lui en avait donné l'audace", v. 644). En ce cas, certes, le recoupement ne se fait pas avec une élégie, mais avec les Métamorphoses ; pourtant, là encore, le contexte est celui d'un rendez-vous amoureux, lorsque Thisbé, dans l'obscurité, vient rejoindre Pyrame près du tombeau de Ninus ${ }^{125}$. Ainsi la corrélation se rattache à la tonalité du genre élégiaque et conforte la précédente, en évoquant allusivement la fuite d'Anna comme une fugue pour aller retrouver un amant : dès lors est préfiguré, produisant un effet d'ironie rétrospectif, le rapt dont le personnage va être victime.

Bref, un montage élaboré fait jouer, selon un contraste sous-jacent, l'atmosphère galante qui affleure avec de telles corrélations et le climat épique, lié au surgissement d'un spectre sanglant. Un détail insolite et sans apparente nécessité cristallise la réunion de ces ambiances antithétiques : il est précisé qu'Anna saute par une fenêtre basse (v. 643), lors même que la porte ne semble pas verrouillée, puisqu'elle bat au souffle du vent (v. 642). L'enjeu du nom fenestra, en fin de vers, se mesure au nombre de réminiscences qu'il fédère: on le rencontre, à la même place, dans des passages qui, non seulement appartiennent aux deux genres mis à contribution, mais se rattachent aux deux sortes de registres convoqués, la mort et l'amour. Chez Virgile, fenestras désigne, lors de l'apparition des Pénates à Énée, les ouvertures qui laissent passer largement la lumière de la lune (En. III, 152); chez Tibulle, fenestra est la haute embrasure depuis laquelle est tombée la sœur de Némésis, qui a péri dans l'accident (II, $6,39)^{126}$; dans les Amours, fenestrae sert à décrire l'entrebâillement de la croisée, qui laisse régner une douce pénombre, propice à l'entrée de Corinne (I, 5, 3).

En somme, ce vocable, que la cocasserie de son emploi met en relief, constitue comme un pivot de l'agencement intertextuel, un carrefour des thématiques dont joue le poète, l'emblème d'une hybridation entretenue dans toute la séquence, où règne du même coup une tonalité ambivalente ${ }^{127}$. Cette démarche combinatoire, qui manipule avec brio les corrélations en excluant le rattachement unilatéral à un genre, induit une savante modulation des effets de sens : couplant la légèreté d'une scène intimiste avec le caractère solennel de l'épique, elle convoque à la fois le registre légendaire et le relativise.

Une telle stratégie débouche, au moment où est narrée la disparition d'Anna dans le Numicius, sur un ensemble de recoupements qui mettent le destin de la voyageuse en rapport avec celui d'une autre héroïne, dont l'histoire est intégrée, en guise d'excursus, dans un poème des Amours. En effet une homologie syntaxique notable apparente le récit de l'enlèvement par le dieu à la scène où l'Anio s'unit avec Ilia, la mère de Romulus et Rémus, privée de ses fils par Amulius et abandonnée par Mars (F. III, 647-648 et Am. 
III, 6, 81-82) ${ }^{128}$. De plus, dans le même distique, Ovide a conjugué cette similitude avec un net rappel de l'instant où l'Anio, découvrant Ilia sur sa rive, tombait aussitôt amoureux d'elle (Am. III, 6, 51) ${ }^{129}$.

Grâce à ces rappels des Amours, le destin d'Anna se rattache analogiquement à celui d'une femme délaissée, comme Didon, et surtout persécutée, comme la voyageuse ellemême. Au demeurant, le récit ne se borne pas à établir ainsi un rapprochement localisé : la piste d'une identification potentielle entre les deux héroïnes est amorcée bien plus tôt. En effet, quand Anna se trouve aux prises avec la tempête, comme pour se dérober aux circonstances, elle se cache le visage : un tel geste répète celui d'Ilia, au moment de s'élancer dans le cours d'eau (F. III, 596 et Am. III, 6, 79) ${ }^{130}$.

Cette corrélation, où l'on peut voir une annonce allusive du sort qui attend Anna, est soutenue par un second jalon, qui intervient lors de la rencontre avec Énée. Une indication du v. 604 a provoqué maints débats parmi les commentateurs : la subordonnée précise qu'un personnage s'avance pieds nus, nudo...pede, formule que l'enchaînement normal de la lecture incite à rapporter au héros troyen, mis en scène dans le vers précédent; pourtant un tel détail se justifie mal, Énée n'ayant guère de raison plausible pour arpenter le rivage ainsi déchaussé. Or, même si la construction est beaucoup moins immédiate, la syntaxe n'exclut pas absolument de rattacher le vers en cause à l'hexamètre suivant, où c'est Anna qui est concernée. Il serait alors aisé d'interpréter la notation comme une marque de dénuement associée à son récent naufrage. Or, ainsi que le souligne Giorgio Brugnoli, la même formule figurait dans le pentamètre où était décrite l'arrivée d'Ilia, désemparée, au bord de l'Anio (Am. III, 6, $50)^{131}$; de surcroît elle y était, comme dans les Fastes, associée à l'errance dans un endroit désert ${ }^{132}$. Il n'en reste pas moins que l'enchaînement du passage induit à retenir plutôt Énée comme le sujet de la proposition. Dès lors, c'est un effet d'ambivalence que produit tout ce jeu de recoupements : renvoyant à Ilia, avec laquelle est associée Anna, il projette non moins sur le héros troyen lui-même, par métonymie, une dimension féminine, associée au rapt, suscitant un effet de sens insolite, qui a provoqué la perplexité des commentateurs.

77 En tout état de cause, dans les aventures d'Anna, un ensemble cohérent d'éléments vient rappeler l'élégie III, 6 des Amours. Plus précisément, les repères qui mettent sur la voie d'un rapprochement avec Ilia se situent aux deux extrémités du récit consacré à celle-ci, comme un exemplum des amours entre fleuves et mortelles ${ }^{133}$.

78 La révélation par Anna de sa métamorphose parachève le dispositif, en impliquant cette fois le cadre discursif qui intègre l'histoire d'Ilia dans l'élégie, les reproches que l'amant-poète adresse à la rivière dont la crue l'empêche de rejoindre sa maîtresse. Ovide charge la nouvelle nymphe d'expliciter elle-même son nom, grâce à un calembour pseudo-étymologique entre Anna Perenna et l'ablatif amne perenne, le cours d'eau perpétuel, qu'elle habite désormais (F. III, 654). À première vue, le jeu de mots peut être appréhendé comme une simple fantaisie ludique du poète qui, par la caution peu crédible qu'il apporte au dénouement de la fiction, en exhibe la gratuité ${ }^{134}$. Pourtant, faisant suite aux vers sur le rapt d'Anna, qui reprennent largement Am. III, 6, l'accent mis sur l'adjectif perennis associé à un flot ne va pas sans rappeler comment, dans l'élégie, le poète énonciateur déclarait au torrent qui lui barrait la route que jamais personne ne lui avait souhaité de "couler perpétuellement", perennis eas (Am. III, $6,98)^{135}$. 
Ce recoupement n'est pas anodin, si l'on accepte d'attribuer, à la suite d'Ann Suter, une valeur emblématique au ruisseau brusquement grossi par les pluies. D'après elle, en effet, la métaphore que développait Callimaque, dans son hymne au dieu Apollon ( $H$. II, 108-112), opposant au grand fleuve bourbeux de la poésie cyclique la source limpide d'un poème plus bref et plus subtil, se transforme, à l'initiative d'Ovide, en une petite fiction $^{136}$ : le ruisseau facile à franchir représente la brièveté de la poésie élégiaque, entravée par l'irruption d'un cours trop abondant ${ }^{137}$. À la dramatisation d'un tel obstacle, en Am. III, 6, correspond un poème d'une longueur inusitée, provoquée par la composante narrative qu'il intègre avec l'histoire d'Ilia.

Or, pour les aventures d'Anna, le récit étiologique développé à partir du modèle épique, est comparable à l'élégie dont la crue est causée par la présence d'un épisode légendaire. Mais, dans ce cas, la mise en rapport métaphorique avec un flux permanent s'inscrit dans un contexte positif, comme en témoignent, à l'issue de l'histoire, les réjouissances de ceux qui recherchaient la fugitive (v. 655-656). À cette nuance près, la manière dont Am. III, 6 thématise les particularités génériques méritait donc un rappel dans un ouvrage en distiques élégiaques tel que les Fastes: c'est leur agencement unitaire, où se trouvent intégrés de nombreux récits, qui est alors figuré par le courant continu, dans lequel se fond à présent la nymphe.

Dès lors, l'insistance marquée d'Ovide sur le lien entre le cours d'eau perpétuel et le nom d'Anna Perenna est susceptible d'offrir à la combinaison de réminiscences hybrides au sein de l'épisode la valeur d'un implicite programme poétique. L'élaboration de rapports conjugués avec l'épopée virgilienne et des œuvres élégiaques projette la perspective d'un poème réunissant des traits qui le rattachent aux deux genres sans l'inféoder à l'un ni à l'autre. Envers chacun d'eux se manifeste un rapport distancié : le flux permanent, que suggère l'étymologie inventée par Ovide pour le nom d'Anna Perenna se démarque de l'élégie érotique, tout en rejetant le principe unitaire de la narration épique.

2 En somme, la composition dans les Fastes affiche indirectement son statut intermédiaire $^{138}$ : l'ampleur des sujets, même si elle advient selon des modalités originales, selon un découpage lié à la répartition entre les fêtes du calendrier et un ton distancié correspondant à l'humour continuel de l'énonciation, n'en est pas moins, comme telle revendiquée ${ }^{139}$. De la sorte, se dessine une poétique du mélange, qui échappe au cadre normatif des genres institués, qui s'attache néanmoins à en explorer les ressources, et dont l'autonomie se fonde, suivant une démarche combinatoire, sur la mise en place de multiples liens avec eux.

Les aventures d'Anna sont exemplaires d'une telle approche : l'ensemble du récit, qui est manifestement bâti sur le patron de l'Énéide et lui emprunte maintes formules, est cependant marqué par l'insistante influence de l'élégie, depuis son amorce, avec la septième Héroïde, jusqu'à son dénouement, avec les Amours ${ }^{140}$. C'est pourquoi le terme d'anamorphose semble convenir pour caractériser la transposition du voyage épique, puisque le parcours d'Anna ne saurait être envisagé comme tel que par la référence à un original qui permet d'identifier le même schéma constitutif, alors que, grâce à une distorsion cohérente, les accents héroïques s'édulcorent et se dévoient selon une savante alliance avec les tonalités de l'élégie. Mais les manifestations de celle-ci, en retour, se trouvent bien moins associées au registre érotique qu'à des thèmes légendaires. L'hybridité générique résultant d'une telle dualité ne correspond nullement à un amalgame, où s'additionneraient des correspondances disparates avec 
telle ou telle œuvre, mais s'appuie sur un agencement très structuré, où l'articulation, la complémentarité, voire la coïncidence entre les recoupements avec les deux genres rendent attentif aux effets que produit un tel assemblage.

$\mathrm{Au}$ demeurant, le tissu de relations que les aventures d'Anna entretiennent avec une élégie particulière des Amours ne saurait être envisagé seulement comme le support d'une allégorie métapoétique. Les liens qui rattachent la sœur de Didon au personnage d'Ilia s'inscrivent dans une dynamique de rapports internes aux Fastes. En effet, dans le livre III, le premier épisode met en scène la vestale, au moment où elle va devenir la mère de Romulus et Rémus ${ }^{141}$ : Mars s'unit furtivement à elle, au cours de son sommeil, tandis qu'elle fait un rêve prémonitoire, annonçant le destin des jumeaux (v. 9-40). Les commentaires soulignent l'absence presque totale de recoupements entre ce passage et celui d'Am. III, 6, pourtant consacré au même personnage ${ }^{142}$ : c'est que la situation est tout autre et que les connexions textuelles sont réservées à l'histoire d'Anna, qui sert ainsi de relais dans un enchaînement de liaisons analogiques.

Car le réseau se développe grâce à la seconde anecdote offrant une explication concurrente pour les fêtes d'Anna Perenna; de nouveau, le dieu Mars est mis en scène dans la posture d'un amoureux. C'est alors la vieille Anna de Bovillae qui, à peine divinisée, bafoue le dieu en se faisant passer auprès de lui pour Minerve, dénouement qui réjouit tout le monde, sauf le galant frustré (v. 693-696) : la déconvenue infligée au dieu de la guerre manifeste la distance prise avec le domaine des armes, prolongeant ainsi la destitution d'Énée comme héros dans l'épisode consacré à la sœur de Didon ${ }^{143}$. Ainsi, des histoires successives rejettent à l'arrière-plan deux acteurs qui incarnent les ressorts fondamentaux du genre épique, Mars et le chef troyen, engagés dans des péripéties où la gloire fait défaut, où intervient même une touche de burlesque : la maitrise virile sur le destin est disqualifiée par des intrigues où ce sont les femmes qui tiennent le rôle principal ${ }^{144}$.

Cette inspiration cadre avec le registre que laisse attendre le poète dans son adresse initiale à Mars, éponyme du mois qu'il s'apprête à chanter, quand il le prie de déposer les armes (v. 1-4). Il invoque pour le convaincre l'exemple de Minerve, qui ne garde pas toujours son équipement guerrier, introduisant déjà le personnage qui sera l'enjeu de l'intrigue avec la vieille Anna (v. 5-8). Au début de l'épisode qui suit, l'union de Mars avec Ilia, le récit souligne que le dieu était alors désarmé (inermis, v. 9, répétant l'occurrence du v. 8) ; la circonstance est donc emblématique de la mise à l'écart, dans les Fastes, fût-ce au mois de mars, des thèmes belliqueux ${ }^{145}$.

En fin de compte, on s'aperçoit que le dispositif intertextuel établissant une correspondance entre Anna et Ilia est un élément-clé au sein d'un réseau qui se déploie dans le livre III des Fastes, selon une concaténation de similitudes variées. De façon récurrente s'y projette le thème des arma et l'évocation de la sphère épique, en même temps qu'une distance est marquée envers eux, contestant du même coup l'axiologie qui leur est associée. Ovide joue sur le paradoxe d'avoir à traiter, dans une œuvre dont le sujet et l'organisation se différencient nettement de l'épopée, le mois qui, lié au dieu Mars, appellerait métonymiquement des motifs héroïques. Dès lors, on comprend mieux la stratégie de capture et de déformation qu'il adopte envers l'Énéide: le livre III des Fastes offraitun cadre propice à l'accueil sous-jacent d'un tel poème, que sa célébrité semblait rendre apte à figurer le genre même, sans qu'il puisse être question de simplement reprendre le modèle en abrégé. Le parcours de la réécriture devait donc s'offrir comme un dévoiement du voyage épique. 
Cette démarche sophistiquée, où les thèmes choisis et les détails retenus concourent à un dispositif d'ensemble qui, en s'affranchissant des limites entre les genres, manipule sans cesse des analogies allusives dans une perspective décalée, empêche de prendre au sérieux les valeurs que supportait l'œuvre de référence et, à travers elles, certaines des orientations idéologiques promues par le pouvoir augustéen. On ne saurait en déduire que la posture ovidienne relève d'une transgression délibérée à l'égard des normes en vigueur. Mais la frontière n'est pas toujours facile à tracer entre une posture distanciée, teintée d'humour, et l'irrévérence à laquelle peut aboutir un scepticisme narquois.

\section{6- Leçons d'un parcours de lecture}

89 On a pu mesurer à quel point les motifs issus de l'Énéide, tels qu'ils ressortent en filigrane dans le voyage d'Anna, se trouvent détournés de leur fonction et de leur signification originelles. Ovide, en rejetant le cheminement finaliste, où les destins, les fata, règlent le cours des événements jusqu'à faire attendre l'assomption de la Rome augustéenne, tend à projeter sur la leçon téléologique du poème virgilien une ironie rétrospective.

D'un tel éclairage, le traitement qu'il réserve à la figure d'Énée offre une illustration marquante. Le héros, démuni du prestige qui le caractérisait chez Virgile, est comme prisonnier d'une dette impossible à régler : son implication dans la mort de Didon le pousse à se justifier puis à chercher, mais en vain, dans la personne d'Anna, un substitut qui lui permettrait de se racheter. De fait, la présence fantomatique de la reine suicidée insiste dans tout l'épisode, comme un arrière-plan décisif : elle préside au départ de sa sœur, laisse planer l'ombre d'un remords sur la destinée du chef troyen et finalement le supplante dans son rôle de protecteur, lors de son apparition finale pour sauver Anna.

91 Certes, l'humour constant dont fait preuve le poète dans l'évocation et la continuation du récit virgilien ne suggère nulle hantise qui tenaillerait Énée : sans donner dans le pathétique de l'angoisse, il place le personnage dans une situation ambiguë, qui encourage une relecture critique de son histoire, telle que la racontait Virgile. Le clairobscur où évolue le héros, désormais sevré d'exploits, installé auprès de son épouse, relativise la gloire que la légende lui associait. Et cet infléchissement se conjugue, s'agissant d'Anna elle-même, avec une désinvolture manifeste envers les ressorts de la narration épique : c'est toujours par défaut que la voyageuse est confrontée à des épreuves, dont l'issue, chaque fois, s'avère déceptive. Tout en adoptant le scénario de l'épopée, le récit trompe les attentes qui en accompagnent d'ordinaire les péripéties: un tel écart problématise du même coup la dimension axiologique liée au genre.

92 Ainsi la piste suivie par Ovide, selon une réécriture qui s'affranchit des normes, le conduit à une remise en cause des valeurs. Cependant il semble excessif d'assimiler une telle attitude à un goût du poète pour leur systématique inversion ${ }^{146}$ : plutôt qu'un irrépressible penchant à prendre le contre-pied de toute célébration héroïque, on serait enclin à retenir une persistante incrédulité, conjuguée avec une incessante expérimentation des possibilités narratives, qui conduit à exhiber les failles de la légende, à jouer de façon insolite sur les ressorts de la fiction. C'est pourquoi la représentation du voyage et de l'héroïsme épiques se trouve contestée de l'intérieur plutôt que refusée ou tournée en dérision. 
93 En tout état de cause, la manière dont les aventures d'Anna se démarquent du modèle offert par l'Énéide témoigne, vers la fin du règne d'Auguste, d'un recul critique envers l'une des grandes figures originelles de Rome. Mais, dans la distance prise envers le sérieux des représentations officielles, qui promouvaient telle variante d'une tradition légendaire au rang d'histoire presque sacrée, Ovide n'était sans doute pas un cas isolé. L'iconographie de l'époque révèle qu'il existait même des approches beaucoup plus irrespectueuses que la sienne, quant à la pietas et au destin glorieux d'Énée : une caricature trouvée dans une maison de Pompéi, datée du début de l'empire, reprend la scène fameuse où le héros s'enfuit de Troie, avec Anchise et Ascagne, en attribuant aux trois personnages des têtes de chiens et des corps de singes ${ }^{147}$. Cet exemple peut s'interpréter comme l'effet d'une saturation face à l'envahissant éloge de la pietas, en tant que vertu par excellence, associée au régime augustéen ${ }^{148}$. La prudence, il est vrai, engageait à cantonner ce genre d'imagerie satirique dans l'intimité d'une demeure. Ovide procède avec plus de finesse, non seulement parce qu'il devait faire preuve de modération dans un poème consacré aux fêtes religieuses, mais aussi parce que son profond intérêt pour l'Énéide excluait de pures facéties et plus généralement une réécriture parodique ${ }^{149}$. Il n'en reste pas moins que son approche de la légende manifeste une répugnance à suivre les leçons idéologiques établies.

94 Sa posture est envisageable comme une réponse à la pétrification des récits mythiques, revêtus d'un sens institué : en interrogeant la mouvance des traditions qui s'attachent aux fêtes et à leurs rites, il redonne du jeu à des représentations qui tendaient à se figer. Le risque était de se mettre en porte-à-faux avec les références d'un pouvoir qui, avec la fin du règne augustéen, est marqué par un raidissement. Alors, comme le souligne D. C. Feeney, la tolérance à toute position hétérodoxe était devenue de plus en plus restreinte ${ }^{150}$. Du coup, même si Ovide ne se hasarde à aucune critique ouverte, ne formule jamais de réserve quant à l'ordre établi, le déploiement de son inventivité est porteur d'un scepticisme intrinsèque envers le décorum des cultes rénovés par l'empereur ou les hiérarchies de la morale officielle ${ }^{151}$.

Que ce goût de renouvellement, appuyé sur une tournure d'esprit démystificatrice, ait pu offusquer Auguste et son entourage, on le présume sans peine ${ }^{152}$. Ainsi, lorsqu'Ovide retire au voyage épique sa finalité, il fait peser le soupçon sur les idéaux associés aux légendes ; lorsqu'il y ajoute, comme pour les aventures d'Anna, une fiction de son crû, il remanie sans vergogne un corpus dédié à la glorification de Rome ; lorsqu'il met en concurrence des variantes, comme avec les étiologies multiples assignées aux fêtes d'Anna Perenna, il laisse planer le doute sur la validité de toute explication sacralisée ${ }^{153}$.

Il ne s'agit pas là d'une opposition frontale à l'édifice religieux du principat sur lequel les Fastes prétendent fonder leur enquête, mais d'une prise de distance, inhérente à une pratique de la poésie qui, à travers les jeux de la réécriture, manipule les représentations antérieures, recherche des associations insolites et construit sur cette base un ensemble de résonances dont l'impact était potentiellement contestataire et irrévérencieux ${ }^{154}$. Ainsi le statut intermédiaire des Fastes amène à expérimenter l'hybridation générique ; le choix de sujets qui correspondent à ce principe motive, pour le mois de mars en particulier, une confrontation distanciée avec la sphère épique : rattachée par le thème des combats à l'image traditionnelle du dieu éponyme, elle doit interagir avec les implications du domaine élégiaque. Le maillage analogique, dont on a observé le déploiement dans le livre III, en est la résultante, unissant le motif 
d'un dieu Mars désarmé en même temps qu'érotisé avec une réplique décalée, féminisée, de l'épopée par excellence qu'était devenue l'Énéide ${ }^{155}$.

Dès lors, on conçoit que l'événement historique dont la date coïncide avec la fête d'Anna, l'assassinat de César, aux ides de mars, soit traité sur le mode mineur d'une quasi-prétérition, arborée comme telle (v. 697) : cela dispensait de s'étendre sur la vengeance qu'Octave se faisait fort d'avoir tirée des meurtriers, sur les luttes de la guerre civile ${ }^{156}$. La mention des armes est donc seulement effleurée (v. 705-710), sans qu'il soit question du rôle attribué au dieu de la guerre, avec le vœu par le futur empereur d'un temple pour Mars Ultor ${ }^{157}$.

Cependant, une particularité du scénario montre le soin pris pour intégrer l'épisode au réseau qui rattache entre eux maints passages du livre III : l'intervention pittoresque de Vesta, qui aurait emporté le corps de César, le soustrayant ainsi aux assassins et ne leur laissant qu'une ombre (v. 701-702), peut être envisagée sous cet angle ${ }^{158}$. Relançant l'analogie, le choix de la déesse pour un tel sauvetage reporte le lecteur jusqu'à l'épisode initial. Car c'est une vestale, Ilia, qui est victime de Mars, tandis que la déesse se voile la face lorsque sa prêtresse accouche (v. 45-46) ${ }^{159}$. Ainsi, aux deux extrémités du livre, naissance et mort se répondent, non sans une touche d'humour : le patronage de Vesta supplante la mention du soutien que Mars vengeur aurait apporté au futur Auguste, une telle omission offrant comme une contrepartie du viol sournois que le dieu a perpétré1 ${ }^{160}$. Cet éclairage problématique de la scène initiale, au cours de laquelle a été conçu Romulus, tend à rejaillir sur l'image du fondateur de Rome qui, avec Énée, constitue un repère essentiel pour le pouvoir ${ }^{161}$. D'autant que, dans la suite du livre, lors de l'enlèvement des Sabines, Romulus à son tour emploie la ruse et la violence, agissant à la façon de son père, dont il suit d'ailleurs les conseils, ainsi que Mars lui-même l'explique au poète $\left(F\right.$. III, 198) ${ }^{162}$. En somme, le tropisme analogique conduit à multiplier les correspondances entre des épisodes où l'image du dieu guerrier contraste avec celle qu'en donnait le culte officiel. La mise en cause de cette figure tutélaire culmine dans l'anecdote où il est mystifié par la vieille Anna ${ }^{163}$.

L'Énéide en réduction fabriquée par Ovide s'intègre donc à une trame qui relie diversement maints passages du livre III, en même temps qu'elle illustre, par la combinaison des références élégiaques avec le modèle épique, le mélange inédit qui s'élabore dans les Fastes. Mais ce savant dispositif de corrélations n'est pas réservé à un seul segment de cette œuvre : un principe de structuration plus ample tend à dessiner une architecture globale. En effet les périples d'Anna entretiennent avec le reste des Fastes des rapports qui les inscrivent dans un ensemble cohérent. Au fil des six livres que nous possédons, trois autres voyages maritimes conduisent non moins vers le Latium, comme vers un point d'attraction dans l'espace, divinités ou personnages légendaires. Or leurs protagonistes sont tous associés, directement ou non, à l'histoire d'Énée: d'abord, venus d'Arcadie et vite rejoints par Hercule, Évandre et sa mère, Carmentis, qui, dès son débarquement, prophétise l'arrivée du héros troyen (I, 469-542) ; plus tard, depuis l'Asie, la grande Mère, Cybèle, qui, précise Ovide, avait choisi de laisser partir Énée avec les Pénates de Troie, alors qu'elle aurait pu l'accompagner, mais qui gagne ensuite Rome à son tour, conformément aux destins (IV, 255-348) ${ }^{164}$; finalement, moins attendue, la tante et nourrice de Bacchus, Ino la Thébaine, tourmentée par Junon, qui obtient avec son fils, Mélicerte, la protection d'Hercule, d'Évandre et de Carmentis, pour s'installer dans le Latium sous le nouveau nom de Mater Matuta (VI, 481-550). 
100 En comptant le périple d'Anna, quatre histoires de voyages, réparties entre les livres extrêmes et médians des Fastes, se correspondent. Ce n'est pas le lieu d'inventorier leurs ressemblances ; il suffit de noter, à titre d'exemple, le flagrant rapport qui rattache aux aventures d'Anna celles d'Ino, avec leur commune amorce par le verbe arserat, évoquant Didon qui brûle de sa passion pour Énée, puisSémélé que consume la vue de Jupiter (III, 545 et VI, 485) ${ }^{165}$.

101 Ce repérage débouche sur la perspective d'une organisation d'ensemble à plusieurs niveaux, où les épisodes nouent des liens complexes, tant à l'intérieur d'un livre qu'avec d'autres livres. Il confirme la piste de recherche proposée par Carole Newlands pour qui, à défaut d'une articulation narrative conforme à celle de l'épopée, c'est dans la structure de l'œuvre, à travers l'examen de ses innombrables connexions à distance, qu'il importe de chercher un principe unificateur ${ }^{166}$.

102 En définitive, on peut saluer, dans les aventures d'Anna la voyageuse, la prouesse d'un récit où la fantaisie se conjugue avec une composition remarquablement rigoureuse, aussi bien dans le réglage de l'ordonnance interne que dans le jeu complexe des réminiscences. Si l'épisode, en première lecture, laisse percevoir nombre de bizarreries et d'anomalies apparentes, celles-ci deviennent intelligibles à mesure que l'on découvre leur cohérence avec la stratégie d'écriture. Les entorses aux attentes fictionnelles et narratives, suscitées par la référence manifeste à un modèle épique, éclairent indirectement la logique à l'œuvre et permettent un regard distancié sur les valeurs et les ressorts de l'Énéide elle-même. Ainsi les tribulations d'Anna se présentent comme un miroir déformant qui, de façon paradoxale, donne une image assez distincte des normes génériques, en tant qu'elles sont refusées ou détournées, passées au filtre de l'hybridation, avec une inventivité combinatoire qui revigore le jeu poétique.

Sans se prendre au sérieux mais avec le sérieux d'une écriture maîtrisée, Ovide offre au lecteur, suivant ce voyage en anamorphose, une sorte de visite guidée, teintée d'impertinence, à travers l'Énéide, qui vaut en même temps comme une illustration de sa propre démarche.

\section{BIBLIOGRAPHIE}

Albrecht, Michael Von, « Ovidio », Enciclopedia Virgiliana, Roma, (1984) 1996, vol. 3, p. 907-909.

Alton, E. H., Wormell, D. E. W., Courtney, E., « Problems in Ovid's Fasti », Classical Quarterly, 23, 1973, p. 144-151.

Anna, Giovanni D', «Anna», Enciclopedia virgiliana, Roma, (1984) 1996, vol. 1, p. 178-182.

Austin, Roland Gregory, P. Vergili Maronis Aeneidos liber quartus, Oxford, 1955.

Barchiesi, Alessandro, Il poeta e il principe - Ovidio e il discurso augusteo, Roma - Bari, 1994.

Boyd, Barbara Weiden, Ovid's literary loves - Influence and innovation in the Amores, Ann Arbor, 1997. 
Brugnoli, Giorgio, « Anna Perenna », Cultura poesia ideologia nell'opera di Ovidio, a cura di Italo Gallo

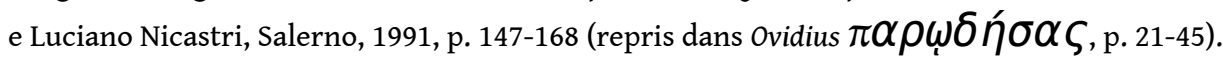

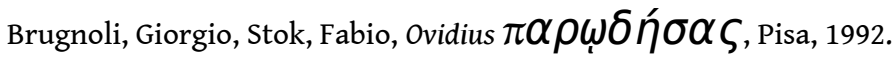

Coarelli, Filippo, Guide archéologique de Rome, (Roma/Bari, 1980) Paris, 1994.

Connors, Catherine, « Ennius, Ovid and representations of Ilia », Materiali e discussioni per l'analisi dei testi classici, 32, 1994, p. 99-112.

Devallet, Georges, «"Anne, ma sœur Anne !" ou les avatars des deux Anna dans la mythologie des Romains ", Vbique amici, Mélanges offerts à Jean-Marie Lassère (préparés sous la direction de Christine Hamdoune), Montpellier, 2001, p. 403-416.

Dumézil, Georges, Le festin d'immortalité - Étude de mythologie comparée indo-européenne, Paris, 1924.

Duret, Luc, Néraudau, Jean-Pierre, Urbanisme et métamorphoses de la Rome antique, Paris, 1983.

Eikhenbaum, Boris, «La théorie de la "méthode formelle" », Théorie de la littérature, textes des Formalistes russes, Paris, 1965, p. 31-75.

Fantham, Elaine, « The role of Evander in Ovid's Fasti », Arethusa, 25, 1992, p. 155-171.

Feeney, D. C., « Si licet et fas est : Ovid's Fasti and the problem of free speech under the Principate ", Roman poetry \& propaganda in the age of Augustus, edited by Anton Powell, London, 1992, p. 1-25.

Frécaut, Jean-Marc, L'esprit et l'humour chez Ovide, Grenoble, 1972.

Genette, Gérard, Palimpsestes, Paris, 1982.

Gowers, Emily, « Talking trees : Philemon and Baucis revisited », Arethusa, 38, 2005, p. 331-365.

Greimas, Algirdas Julien, Sémantique structurale, Paris, (1966) édition revue et corrigée,1974.

Harries, Byron, « Causation and the authority of the poet in Ovid's Fasti », Classical Quarterly, 38, 1989 , p. 164-185.

Herbert-Brown, Geraldine, Ovid and the Fasti - an historical study, Oxford, 1994.

Hinds, Stephen, « Generalising about Ovid », Ramus, 16, 1987, p. 4-31.

Hinds, Stephen, « Arma in Ovid's Fasti », Arethusa, 25, 1992, p. 81-153.

Hinds, Stephen, Allusion and intertext, Cambridge, 1998.

Johnson, W. R., « The desolation of the Fasti », Classical Journal, 74, 1978, p. 7-18.

Lee-Stecum, Parshia, « Roman refugium : refugee narratives in Augustan versions of Roman prehistory », Hermathena, 1, 2008, p. 69-91.

Ling, Roger, Roman painting, Cambridge, 1991.

Manaï, Nadia, Les origines romaines dans les Fastes d'Ovide : un labyrinthe narratif, mémoire de Master, Université de Nantes, 2011.

Marangoni, Claudio, « Di come Ovidio sia andato alla festa di Anna Perenna assieme a Virgilio », CentoPagine, 1, 2007, p. 1-7.

McKeown, James C., « Fabula proposito nulla tegenda meo : Ovid's Fasti and Augustan politics », Poetry and politics in the age of Augustus, ed. A. J. Woodman \& D. A. West, Cambridge, 1984, p. 169-187.

Merli, Elena, Arma canant alii - Materia epica e narrazione elegiaca nei Fasti di Ovidio, Firenze, 2000. 
Murgatroyd, Paul, Mythical and legendary narrative in Ovid's Fasti, Leiden - Boston, 2005.

Murgia, Charles E., « Dido's puns », Classical Philology, 82, 1987, p. 50-59.

Myers, K. Sara, Ovid, Metamorphoses, Book XIV, New York, 2009.

Newlands, Carole, « Ovid's narrator in the Fasti », Arethusa, 25, 1992, p. 33-54.

Newlands, Carole, « Transgressive acts : Ovid's treatment of the Ides of March », Classical Philology, 91, 1996, p. 320-338.

Newlands, Carole E., Playing with time - Ovid and the Fasti, Ithaca and London, 1995.

Newlands, Carole, « Connecting the disconnected : reading the Fasti », Intratextuality - Greek and Roman textual relations, edited by Alisson Sharrock and Helen Morales, Oxford, 2000, p. 171-202.

Peeters, Félix, Les « Fastes » d'Ovide - Histoire du texte, Bruxelles, 1939.

Perea, Sabino, « Anna Perenna : religión y ejemplaridad mítica », Espacio, tiempo y forma, Serie II, Historia antigua, 11, 1998, p. 185-219.

Philips, Charles Robert, « Rethinking Augustan poetry », Latomus, 42, 1983, p. 780-813.

Piranomonte, Marina, « Anna Perenna a dieci anni della scoperta », MHNH, 9, 2009, p. 251-264.

Porte, Danielle, L'étiologie religieuse dans les Fastes d'Ovide, Paris, 1985.

Poulle, Bruno, « La nouvelle Énéide d'Ovide dans les Fastes (I, 461-586) », L'intertextualité, Études réunies et présentées par Nathalie Limat-Letellier et Marie Miguet-Ollagnier, Besançon, 1998, p. 65-72.

Ross, David O., Backgrounds to Augustan poetry: Gallus, Elegy and Rome, Cambridge, 1975.

Saint Denis, Eugène De, Le rôle de la mer dans la poésie latine, Paris, 1935.

Salvadori, Monica, « Diffusion du "deuxième style" ", La peinture romaine de l'époque hellénistique à l'Antiquité tardive, Arles, 2003, p. 114-131.

Soler, Joëlle, Écritures du voyage, Paris, 2005.

Stok, Fabio, «L’alternativa dei Fasti », Ovidius $\pi \alpha \rho \varphi \delta \eta ́ \sigma \alpha \varsigma$, Pisa, 1992, p. 47-73.

Stok, Fabio, « Lo spettacolo degli ancilia », Nunc teritur nostris area maior equis - Riflessioni sull'intertestualità ovidiana - i Fasti, a cura di Luciano Landolfi, Palermo, 2004, p. 69-79.

Suter, Ann, « Ovid, from image to narrative : Amores 1.8 and 3. 6 », The Classical World, 83, 1989, p. 15-20.

Swallow, Ellenor, « Anna Soror », Classical Weekly, 44, 1951, p. 145-150.

Tronchet, Gilles, La métamorphose à l'œuvre - Recherches sur la poétique d'Ovide dans les Métamorphoses, Louvain - Paris, 1998.

Tronchet, Gilles, « À la croisée des chemins (Ovide, Métamorphoses : livre XIV), Vita Latina, 185-186, 2012, p. 3-31.

Tronchet, Gilles, «Fiction de témoins et témoins de fiction : Achéménide et les Troyens (Virgile, Énéide, III, 554-691), Théories et pratiques de la fiction à l'époque impériale, Textes réunis par Christophe Bréchet, Anne Videau et Ruth Webb, Paris, 2013, p. 137-167.

Wiseman, Timothy Peter, « Documentation, visualization, imagination : the case of Anna Perenna's cult site », Imaging ancient Rome : documentation - visualization - imagination , L. 
Hasselberger, J. Humphrey, Journal of Roman archaeology, suppl. series 61, Portsmouth, 2006, p. 51-61.

Zanker, Paul, Un'arte per l'impero, Milano, 2002.

\section{ANNEXES}

Annexe 1

\section{Recoupements entre l'amorce du récit, la fin de la septième Héroïde et les dernières paroles d'Anna dans l'Énéide}

Ovide, Fastes III, 545-554

Les termes soulignés sont communs avec $H$. VII, les termes graissés avec En. IV.

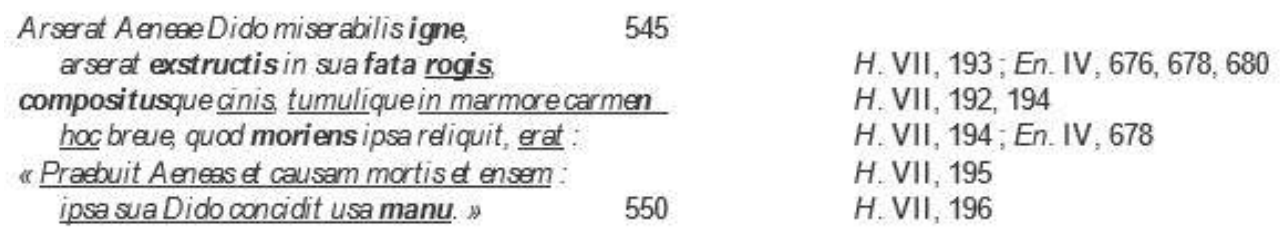

La malheureuse Didon avait brûlé de ses feux pour Énée, elle avait brûlé sur le bûcher préparé pour accomplir son destin, et sa cendre avait été déposée au tombeau, tandis que sur le marbre de celui-ci, il y avait ce bref poème qu'elle-même, en mourant, avait laissé : 'C'est d'Énée que sont venues la cause de sa mort ainsi que l'épée. Mais c'est de sa propre main que Didon a péri.'

Ovide, Héroïdes VII, 191-196

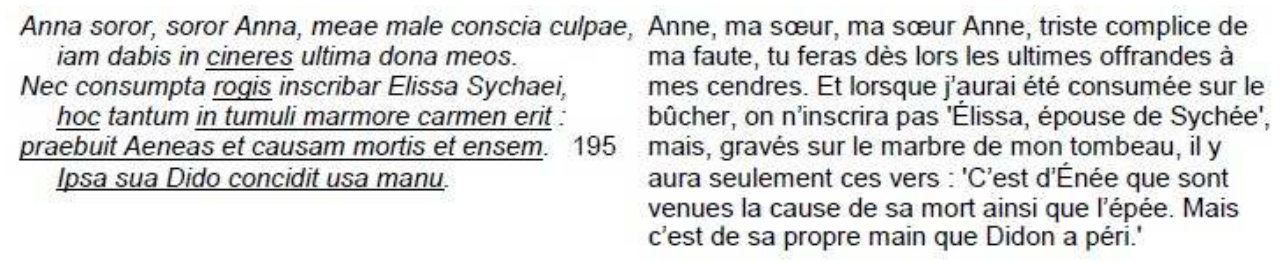

Virgile, Énéide IV, 676-681

Hoc rogus iste mihi, hoc ignes araeque parabant ? Quid primum deserta querar? Comitemne sororem spreuisti moriens? Eadem mead fata uocasses, idem ambas ferro ddor atque eadem hora tuliset His etiam struxi manibus patriasque uocaui uoce deas, sic teut posita, cruddis, abessem?
Voilà donc ce que me réservaient ce bûcher que tu voulais et les feux des autels? Quelle plainte lancer en premier, dans mon abandon? En mourant, tu as dédaigné de prendre ta sœeur pour compagne? II

680 t'aurait suffi de m'appeler à un même trépas et au même instant le fer nous aurait emportées toutes deux, victimes d'un même chagrin. Et c'est de mes mains que j'ai fait ces préparatifs en invoquant à pleine voix les dieux ancestraux, pour que tu reposes ainsi, cruelle, et que je sois séparée de toi ?

Annexe 2 


\title{
Les aventures d'Anna : un plan dédoublé
}

\author{
545-550 préambule : mort de Didon rappelée (enchaînement avec la fin de la septième Héroïde) \\ 551-600 errances d'Anna \\ 551-564 occupation de Carthage par larbas; Anna doit s'exiler, après avoir invoqué les mânes de \\ Didon \\ 565-578 étape à M alte (accueil de Battus) ; menacée par Pygmalion, Anna doit repartir \\ 579-600 arrivée dans le sud de l'Italie; emportée par une tempête jusqu'au Latium, Anna échappe au \\ naufrage \\ 601-648 Anna dans le Latium \\ 601-624 sur le rivage, rencontre avec Ėnée (dont l'accueil redouble celui de Battus) \\ 625-638 dans la demeure d Énée, haine de Lavinia (dont la menace redouble celle de Pygmalion) \\ 639-648 apparition du spectre de Didon (dont la venue redouble la cérémonie consacrée à ses \\ mânes) ; ultime fuite d'Anna, enlevée par le Numicius (dont le flot redouble celui de la tempête) \\ 649-656 épilogue : métamorphose d'Anna (répondant à la mort de Didon et s'achevant de la même \\ manière sur des paroles de la disparue)
}

Annexe 3

\section{Analogies entre les aventures d'Anna et celles d'Énée : schémas parallèles}

Anna (Fastes)
Prise de Carthage
M ânes de Didon : adieux de l'héroïne
Regard en s'en allant sur les remparts de Carthage
Accueil et séjour sur l'île de Malte
Fuite devant les menaces de Pygmalion
Presque arrivée en Italie, calme précaire
+ Emportée par une tempête
Débarquement dans le Latium
Rencontre d'Énée et d'Achate avec Anna
Anna raconte à Énée ses errances (un seul vers)
+ Hospitalité d'Énée offrant à Anna des cadeaux
Haine de Lavinia contre Anna
Apparition salvatrice de Didon
Perte d'Anna, liée à l'amour et causée par Énée
[M étamorphose d'Anna dans le Numicius]

\author{
Énée (Énéde)
}

Prise de Troie (livre II)

Ombre de Créüse : adieux du héros (livre II)

Regard en s'en allant sur les remparts de Carthage (livre V)

Accueil à Délos, séjour en Crète (livre III)

Fuite à cause d'une épidémie (livre III)

Calme précaire après une tempête (livre III)

+ Presque arrivé en Italie, emporté par une tempête (livre I)

Débarquement à Carthage (livre I)

+ Débarquement dans le Latium (livre VII)

Rencontre de Vénus avec Ėnée et Achate (livre I)

Hospitalité de Didon recevant des cadeaux d'Énée (livrel)

+ Enée raconte à Didon ses errances (livres II et III)

Haine d'Amata et Turnus contre Énée (livre VII)

Apparition salvatrice d'Hector (livre II)

Perte de Didon, liée à l'amour et causée par Énée (livre IV)

[Métamorphose d'Énée dans le Numicius, Ovide M. XIV]

Annexe 4

\section{Recoupements frappants avec l'élégie III, 6 des Amours}

Le graissage indique une communauté de vocables entre Am. III, 6 et F. III, le soulignement une analogie de construction.

Ovide, Fastes III, 647-648
Corniger hanc tumidis rapuisse Numicius undis creditur et stagnis occuluisse suis.

Le Numicius, porteur de cornes, l'enleva, croiton dans ses flots gonflés, et la cacha au sein de ses eaux. 


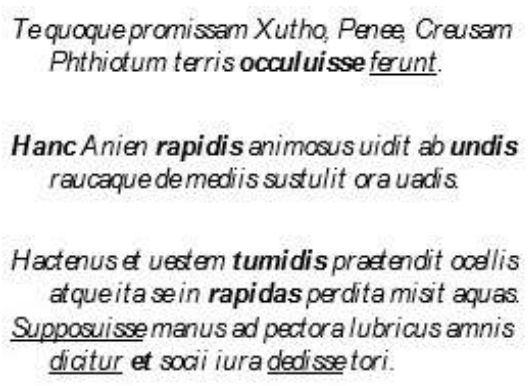

\author{
Toi aussi, Pénée, on raconte que, dans les terres \\ de la Phthiotide, tu cachas Créüse, promise à \\ Xouthos. \\ L'Anio impétueux, du sein de ses flots fou- \\ gueux, la vit et, du milieu des ondes, \\ éleva sa bouche à la voix rude. \\ Elle se tut et, d'un pan de son vêtement cachant \\ ses yeux gonflés, se jeta, éperdue, au sein des \\ eaux impétueuses. Le souple cours d'eau, dit- \\ on, de ses mains, soutint sa poitrine et lui \\ donna de partager sa couche, selon une union \\ légitime.
}

\section{NOTES}

1. Il convient d'emblée de remercier les rapporteurs de la revue Dictynna pour leurs fructueuses remarques ; les lacunes et les inadvertances qui subsistent sont imputables au seul signataire.

2. Sur les découvertes archéologiques à Rome, piazza Euclide, d'une fontaine et d'un autel dédiés à Anna Perenna, qui témoignent d'un culte encore florissant au $2^{\text {ème }}$ siècle de notre ère, voir la synthèse de Marina Piranomonte, «Anna Perenna a dieci anni della scoperta ». Selon Timothy P. Wiseman, le lieu de la découverte ne coïncide pas avec l'emplacement évoqué par Ovide dans les Fastes («Documentation, visualization, imagination: the case of Anna Perenna's cult site», p. 54-55).

3. Bien avant d'établir sa théorie trifonctionnelle, Georges Dumézil, en rattachant à l'annone le nom de la déesse, envisageait celle-ci comme une personnification de la puissance nourricière (Le festin d'immortalité, p. 133). Beaucoup plus récemment, Sabino Perea, selon une perspective assez proche, évoque une puissance vitale de renouvellement («Anna Perenna: religión y ejemplaridad mítica ", p. 191).

4. La date correspond à celle des Fasti Vaticani, remontant à l'époque de Tibère (CIL I ${ }^{2}$, p. 242). Une autre, celle du 18 juin, est fournie par le calendrier tardif de Furius Filocalus (CIL $\mathrm{I}^{2}$, p. 266). Timothy $\mathrm{P}$. Wiseman émet l'hypothèse d'un changement intervenu entre le $1^{\mathrm{er}}$ et le $4^{\text {ème }}$ siècles («Documentation, visualization, imagination: the case of Anna Perenna's cult site», p. 60). Carole Newlands souligne à quel point l'évocation de la fête populaire s'inscrit dans une ambiance carnavalesque, contrastant avec le sérieux des cérémonies officielles («Transgressive acts : Ovid's treatment of the Ides of March », p. 324).

5. Dans les quatre vers qui s'intercalent sont juste mentionnées les autres possibilités : la Lune, Thémis, Io et une nymphe Azanide, qui aurait servi de nourrice à Jupiter. Devant un tel foisonnement, il semble que la fonction exacte d'Anna Perenna ne puisse être aisément définie, même si le manque d'informations sur la déesse incite à faire feu de tout bois. C'est pourquoi les approches interprétatives, qui sont basées, pour l'essentiel, sur le passage ovidien, s'exposent au risque de solliciter quelque peu les données, lorsque l'effort pour concilier plusieurs de ces choix les entraîne sur la voie de l'extrapolation. Par exemple, quand Georges Dumézil privilégie l'aspect alimentaire, il insiste sur la connexion entre la nourrice de Jupiter et la vieille Anna (Le festin d'immortalité, p. 132-133); Sabino Perea, s'inspirant de Mircea Eliade, favorise de son côté un symbolisme des échanges entre la vie et la mort, en associant la sœur de Didon, changée en nymphe aquatique et la Lune (il est vrai qu'il cherche ensuite à conjuguer cette approche avec celle de Georges Dumézil : "Anna Perenna : religión y ejemplaridad mítica », p. 190-194). C'est sans compter avec l'humour ovidien, qui se plait à mettre en scène dans les Fastes la précarité de la tradition et en profite notamment pour imaginer une histoire dérivée de l'Énéide. 
6. On sait que la statue d'Énée faisait face à celle de Romulus, chacune étant placée dans les niches centrales des exèdres, sur le Forum d'Auguste, de part et d'autre du temple de Mars Ultor (Luc Duret et Jean-Pierre Néraudau, Urbanisme et métamorphoses de la Rome antique, p. 111-112; Filippo Coarelli, Guide archéologique de Rome, p. 79-81). Ovide lui-même évoque cet agencement (F. V, 562-566).

7. Paul Murgatroyd considère cette restriction du rôle majeur qu'Énée aurait pu jouer dans les Fastes comme la marque d'un esprit réfractaire à l'idéologie augustéenne (Mythical and legendary narrative in Ovid's Fasti, p. 120).

8. Parshia Lee-Stecum dresse l'inventaire des références bibliographiques récentes à propos de cette relation intertextuelle et de son appréciation («Roman refugium: refugee narratives in Augustan versions of Roman prehistory ", p. 85, n. 33).

9. Les prologues adressés à Germanicus et Auguste (I, 13-14 et II, 15-16) l'attestent, ouvrant la voie pour une telle ambivalence. Aussi Geraldine Herbert-Brown, en ramenant la dimension ludique des Fastes au simple souci d'agrémenter l'éloge de la famille impériale, adopte-t-elle une approche interprétative difficile à tenir (Ovid and the Fasti, p. 30 notamment). Car la dynamique même de la composition, par le recul qu'elle amène à prendre, en particulier dans la réécriture et dans la confrontation de variantes, outrepasse le discours affiché. Si elle n'implique pas une mise en cause clandestine, elle détermine malgré tout un scepticisme foncier. En fait, ainsi que nombre de commentateurs l'ont souligné à juste titre, l'effort pour ramener la démarche d'Ovide à celle d'un opposant ou bien d'un adepte du régime, voire d'un artiste uniquement soucieux de réussite littéraire, engage dans un faux débat (Giorgio Brugnoli, Fabio Stok, Ovidius $\pi \alpha \rho \omega \delta \eta ́ \sigma \alpha \varsigma$ , p. 17 ; Byron Harries, "Causation and the authority of the poet in Ovid's Fasti », p. 165). Comme le préconise Carole Newlands, plutôt que d'assigner au poète une attitude invariable, il importe d'élucider les règles du jeu poétique et d'observer à chaque fois la signification induite (Playing with time, p. 8-9).

10. De la sorte, l'action se rattache à la part de l'intrigue virgilienne la moins caractéristique d'une épopée, le livre IV de l'Énéide, où se déploie la passion amoureuse et qui, du reste, selon Ovide lui-même, avait la prédilection du public (Tr. II, 533-536). Comme le souligne Alessandro Barchiesi, Ovide se montre sans cesse attentif à discerner, dans les poèmes de ses prédécesseurs, un double registre, passible d'une lecture différenciée (Il poeta e il principe, p. 18).

11. Du reste, cet ultime événement sort du cadre diégétique de l'Énéide, le lien entre la mort du héros et les eaux du Numicius pouvant renvoyer à une version écartée par Virgile, mais restituée par Denys d'Halicarnasse (Ant. Rom. I, 64, 4-5), où Énée, après avoir mis à mort Turnus, disparaissait mystérieusement sur les bords de cette rivière, au cours de la lutte contre Mézence (K. Sara Myers, Ovid, Metamorphoses, Book XIV, p. 154).

12. On peut mettre en rapport cette démarche avec l'ingéniosité dont il fait preuve, dans le livre XIV des Métamorphoses, quand, redoublant la création par Virgile d'un compagnon d'Ulysse, inconnu de l'Odyssée, Achéménide, grâce à Macarée, qui avait lui aussi partagé les errances du roi d'Ithaque, il met en scène la rencontre des deux personnages (sur la correspondance entre une telle réduplication et la structure du livre, Gilles Tronchet, « À la croisée des chemins », p. 6-11).

13. Ainsi que le note Carole Newlands, c'est une figure paternelle, origine de l'état romain, étroitement liée au programme idéologique et monumental d'Auguste, qui est ainsi bafouée (« Transgressive acts: Ovid's treatment of the Ides of March », p. 331).

14. Est alors passée sous silence l'implication décisive attribuée à Mars dans la vengeance que l'empereur se glorifiait d'avoir tirée des assassins, tandis que l'intervention de Vesta est mise en avant (F. III, 695-696), selon un rapprochement insolite de la chaste déesse avec les réjouissances et les plaisanteries obscènes qui étaient censées honorer le souvenir de la ruse ourdie par Anna Perenna (Carole Newlands, "Transgressive acts: Ovid's treatment of the Ides of March », p. 333-335). L'appel du futur Auguste au dieu de la guerre, vouant en la circonstance le temple de Mars Ultor, est reporté par Ovide à la description de ce sanctuaire (V, 569-578). 
15. Elle y offre une occurrence exceptionnelle : parmi les vingt-quatre métamorphoses évoquées dans cette œuvre, presque toutes relèvent de catastérismes ou redoublent un récit des Métamorphoses, les deux catégories se conjuguant parfois ; le seul autre épisode échappant à une telle régularité, c'est, non sans analogie avec le sort d'Écho, dans le livre III des Métamorphoses, celui du mutisme infligé à Lara, dès lors appelée Muta (F. II, 585-616 ; v. 598, une allusion à Ilia, changée en nymphe aquatique, établit un rapport avec Anna Perenna).

16. Il est vrai que l'existence d'un culte d'Anna Perenna près du Numicius conduisait à rapprocher la déesse et la fin d'Énée, devenu Indigète (Danielle Porte, L'étiologie religieuse dans les Fastes d'Ovide, p. 144). Ainsi, l'équivalence entre la sœur de Didon et Anna Perenna recevait un soutien fictionnel. D'où l'hypothèse que la recherche d'une correspondance avec l'apothéose d'Énée, contée dans le livre XIV des Métamorphoses, a entraîné Ovide à faire disparaître Anna dans le Numicius, comme dénouement pour une histoire qu'il avait sans doute imaginée (Giorgio Brugnoli, « Anna Perenna », p. 148-149).

17. Ovide n'introduit que deux acteurs nouveaux, distribués entre les deux volets du récit: Battus, roi de Malte, qui recueille Anna, mais sans avoir le courage de la défendre contre Pygmalion (v. 570-578), et le dieu-fleuve Numicius, qui l'enlève et la cache dans ses flots (son nom figure dans l'Énéide, mais pour mentionner le cours d'eau).

18. Elles sont concentrées dans le livre IV; Paul Murgatroyd y a relevé les pistes ainsi utilisées par Ovide (Mythical and legendary narrative in Ovid's Fasti, p. 130).

19. Le retour au nominatif du nom propre Numidae (En. IV, 41 et F. III, 551) voisine avec la mention renouvelée de Iarbas, qui "se souvient d'avoir été dédaigné", seque memor spretum (v. 553). Cette formule est porteuse d'une allusion à la mémoire dont fait preuve le texte envers l'énoncé de Virgile, despectus Iarbas (En. IV, 36), suivant le principe d'une "alexandrian footnote" (David O. Ross, Backgrounds to Augustan poetry, p. 78 ; Stephen Hinds, Allusion and intertext, p. 1-5). Plus précisément encore, Iarbas se remémore à cette occasion, non sans un effet d'ironie, les propos indignés que lui-même tenait dans l'Énéide : il emploie le verbe reppulit, v. 554, repris à En. IV, 214. En outre, le potitur qui, dans le récit, l'évoque en train d'investir le palais de Didon (v. 552 ), provient du même discours, où Iarbas, dépité, l'appliquait à Énée (En. IV, 217). À ces réminiscences vient s'ajouter, selon une autre forme d'écart ironique, un écho de la déclaration où Énée lui-même assurait qu'il se souviendrait toujours de celle qu'il nomme Elissa (En. IV, 335-336 et F. III, 553, reprise à la même place de la forme Elissae).

20. Plus loin, Didon rappelait le double péril dont Anna lui avait parlé (En. IV, 325-326) : la formule Gaetulus Iarbas, dans le second vers, paraît avoir autorisé la variante ovidienne Maurus Iarbas (F. III, 552), où l'adjectif Maurus semble, quant à lui, provenir du discours de Iarbas (Maurusia (gens), En. IV, 206). C'est aussi un terme d'En. IV, 325 que reprend le vocable frater (F. III, 577 et 580), utilisé au lieu de germanus (En. IV, 44). De la sorte, non content de s'appuyer sur des passages qui évoquent Anna chez Virgile, Ovide agence un entrelacs d'échos par rapport au livre IV de l'Énéide, empruntant divers détails à chacun des trois passages où se trouve mentionné Iarbas.

21. Iussa fugit uentoque ratem commitit et undis ("Obéissant à l'injonction, elle fuit et confie son navire au vent et aux flots"). Le participe initial offre un écho à la question que se pose Didon, iussa sequar? ("dois-je suivre les injonctions... ?", En. III, 538), même si, chez Virgile, iussa est un nom; le verbe fugit répond à l'ablatif fuga (En. III, 543); enfin uentoque ratem committit reprend la perspective qu'envisageait la reine d'"offrir ses voiles aux vents", uentis dare uela (En. III, 546).

22. On a vu parfois dans cette indication l'affleurement allusif d'une variante légendaire, mentionnée dans une scholie de Servius (ad Aen. V, 4) et relayée par un commentaire du Servius auctus (ad Aen. IV, 682), où, d'après Varron, Anna aurait eu avec le héros une liaison. Pour Georges Devallet, le rapprochement semble forcé : Didon ne fait que mettre en avant l'aptitude qu'Anna possède à jouer le rôle d'intermédiaire («"Anne, ma sœur Anne !” ou les avatars des deux Anna dans la mythologie des Romains », p. 404-406). Cette réserve n'interdit pas de penser qu'Ovide ait 
pu avoir connaissance de la tradition rapportée par Varron, ce qui aurait motivé la haine immédiate que Lavinia éprouve envers Anna. Mais, ainsi que le suggérait Servius, la chronologie varronnienne, comme elle situe la fondation de Carthage plusieurs siècles après la chute de Troie, s'oppose à l'existence d'une idylle entre la sœur de Didon et le héros virgilien. Georges Devallet pense résoudre la difficulté en dissociant l'Anna carthaginoise de celle aimée par Énée, qui se ramènerait à la seule divinité italique, Anna Perenna (loc. cit., p. 407). Cela oblige à supposer qu'Ovide, s'il n'a pas confondu les deux personnages, a choisi de brouiller les cartes en identifiant la déesse avec la sœur de Didon. Une telle hypothèse ne va pas sans soulever une objection : si l'on admet que le poète ait songé à un lien amoureux avec Énée, pourquoi, comme le remarque Giorgio Brugnoli («Anna Perenna », p. 148, n. 2), ne l'a-t-il pas évoqué, même incidemment, au lieu de se focaliser sur la haine jalouse de Lavinia, qui se solde par une union toute différente avec le dieu-fleuve Numicius?

23. Le récit souligne, non sans humour, la stupéfaction du héros lorsqu'il la reconnaît ( $F$. III, 605-606).

24. Il est à noter que la formulation recoupe celle d'un passage virgilien concernant Anna, qui n'appréhendait pas de geste désespéré : Nec timui de morte tamen ("Cependant, je ne redoutais pas sa mort", F. III, 617), en regard de Non tamen Anna.../......grauiora timet quam morte Sychaei ("Cependant, Anna... ne redoute pas de réaction pire qu’à la mort de Sychée", En. IV, 500, 502).

25. La forme identique, felix, se trouve dans un hexamètre, à la même place que la seconde occurrence virgilienne, après la coupe penthémimère. Comme le note Paul Murgatroyd (Mythical and legendary narrative in Ovid's Fasti, p. 105), l'adjectif évoque non moins son opposé, infelix, régulièrement associé par Virgile à Didon (En. I, 749; IV, 68, 596 ; VI, 456).

26. Les formules apparentées occupent, dans les deux cas, une fin de vers. Didon menaçait de poursuivre sans cesse Énée, lorsqu'elle ne serait plus qu'une ombre (En. IV, 386). Ovide la fait justement revenir sous cette forme, en lui attribuant cependant un rôle de protectrice à l'égard d'Anna.

27. C'est à elle, comme le note Ellenor Swallow, que reviennent les dernières paroles dans le livre IV de l'Énéide (« Anna Soror », p. 150). Le v. 683 annonce non moins la perte de Carthage, déjà évoquée v. 669-670, si bien que l'amorce et l'issue de l'épisode ovidien trouvent à la fois leur raison d'être en cet ultime propos.

28. Prenant la formule au pied de la lettre, Charles E. Murgia l'interprète comme la référence implicite à une tradition déjà connue de Virgile («Dido's puns », p. 59). C'est faire un amalgame entre certains doubles sens, renvoyant allusivement dans l'Énéide à d'autres passages, et les possibilités de prolongements fictionnels que le poème était susceptible d'offrir et qu'Ovide a mobilisées de façon originale. La liberté avec laquelle le poète des Fastes a repris le modèle virgilien ne permet guère de postuler, comme le fait Charles $\mathrm{E}$. Murgia, qu'une légende préétablie sur le devenir d'Anna aurait guidé sa composition (loc. cit., p. 58).

29. Ainsi, comme l'indique Giovanni d'Anna, la figure d'Anna est traitée dans l'Énéide de la même manière que celle de Chalciopé, sœur et confidente de Médée, dans les Argonautiques d'Apollonios de Rhodes ("Anna », p. 180); même si l'approche des deux personnages comporte de notables différences (Roland Gregory Austin, P. Vergili Maronis Aeneidos liber quartus, p. 28), leur impact est similaire et c'est en suivant l'exemple de Médée, que Didon impute sa conduite aux avis de sa sœur (En. IV, 548-549, d'après Arg. IV, 734).

30. Ellenor Swallow, dans un article qui s'affirme, non sans naïveté, comme une réhabilitation de l'Anna virgilienne, conclut par cette phrase : "Though she will continue to live, there is for Anna nothing now left in live." ("Même si elle va continuer à vivre, il n'y a désormais plus rien comme vie pour Anna.", « Anna Soror », p. 150). C'est justement une démonstration du contraire que s'est attaché à fournir Ovide: toutes les fois que la situation d'un personnage reste inaboutie, d'innombrables virtualités s'offrent à l'imagination des loisibles continuateurs. 
31. Palimpsestes, p. 197. Il est vrai que l'analepse est d'une amplitude très modérée, puisqu'elle ne reporte nullement le récit en amont de la diégèse virgilienne. Comme celle-ci demeure inachevée, s'interrompant sur la mort de Turnus, sans que la narration mène jusqu'à la fin de la guerre contre les Rutules, l'épisode ovidien qui, en retrouvant le héros, renoue avec le fil principal, lui apporte un effectif prolongement.

32. Gérard Genette, Palimpsestes, p. 198. Il note plus loin que l'Énéide elle-même pourrait être envisagée comme une continuation en paralepse des épopées homériques (op. cit., p. 202-203). Quant à l'histoire d'Anna, si on la confronte au livre XIV des Métamorphoses, qui suit Énée jusqu'à son élévation au rang des dieux, elle vientseulement combler une lacune intermédiaire: continuation elleptique, en l'occurrence.

33. En elle-même, la posture énonciative d'un tel poème, où l'épistolière se retrouve seule, en train de commenter les circonstances évoquées dans le récit virgilien, entraîne une dimension paraleptique, dont Ovide a joué en virtuose dans la plupart des Héroïdes.

34. Bien entendu, le destinataire de la missive, ayant appareillé, n'aurait pu lui-même s'occuper des funérailles. L'amorce de l'épisode offre ainsi un prolongement savoureux à la fin de l'Héroïde : tout laissait supposer que le courrier n'avait aucune chance de parvenir à destination, mais qu'Anna, l'ayant découvert, aurait soin d'obéir à ces ultimes recommandations ; en s'adressant à sa sœur, Didon semble avoir implicitement prévu que ce serait elle qui lirait sa missive. Cette hypothèse est accréditée par la formule désignant l'épitaphe comme une courte poésie que Didon "elle-même a laissée", ipsa reliquit (F. III, 548 ; avec une pointe d'humour, puisque c'est Ovide, en l'occurrence, qui tenait le calame !). Anna s'acquitte même de ses devoirs une seconde fois, lorsque, au bout de trois ans, elle célèbre à nouveau une cérémonie pour les cendres de sa sœur (F. III, 560-564).

35. La versification élégiaque, en laissant reproduire exactement dans les Fastes le distique de l'épitaphe, facilite le lien entre les deux œuvres. Déjà, dans l'Art d'aimer, les deux vers, sans être répétés, trouvaient un sensible écho dans un passage imputant l'abandon des épistolières que mettent en scène les Héroïdes àun manque de savoir-faire amoureux (III, 39-40). Or le troisième livre prétend fournir aux femmes les atouts nécessaires. Et juste après, une formule conclut le développement: arte perennat amor ("c'est l'art qui rend l'amour pérenne", v. 42). Ainsi l'Art d'aimer, en reliant à la mort de Didon l'occurrence du verbe perennare, préfigure singulièrement la conjonction dans les Fastes d'Anna Perenna avec l'intrigue virgilienne ainsi que la fin de la septième Héroïde.

36. En particulier, l'ablatif igni, à la fin d'En. IV, 2, est repris à la même place par la variante igne en F. III, 545. Lié à cette image, le nominatif Dido se trouve déjà en En. IV, 68, juste après la coupe penthémimère.

37. Voir Annexe 1.

38. Le mot rogus figure v. 676, non loin de la locution ad fata, v. 678 ; évoquant le corps de Didon, le participe posita, v. 681, reçoit un équivalent chez Ovide, à propos de sa cendre, déposée dans le tombeau, compositus (F. III, 547).

39. On a vu plus haut que le v. 682 , associant à cette mort celle d'Anna, programmait en quelque sorte la destinée de cette dernière dans les Fastes.

40. Du reste, comme l'a montré Claudio Marangoni, tout le préambule ovidien qui décrit les festivités d'Anna Perenna ( $F$. III, 523-542), en jouant sur les réminiscences avec l'évocation des abeilles dans les Géorgiques (IV, 158-165), mais surtout avec celle des sujets de Didon bâtissant Carthage dans l'Énéide (I, 421-437), prépare le lien explicite ultérieur avec l'épopée («Di come Ovidio sia andato alla festa di Anna Perenna assieme a Virgilio»). Alertant l'attention des lecteurs férus de Virgile, les similitudes installent un lien métonymique, mais selon une tonalité décalée, à l'image du contraste entre les monuments qui s'édifient dans l'épopée et les frêles huttes où s'abritent ceux qui célèbrent Anna Perenna. On pourrait d'ailleurs ajouter au relevé de Claudio Marangoni plusieurs recoupements associant chez Ovide le lieu des réjouissances aux 
Champs-Élysées contemplés chez Virgile par Énée, notamment F. III, 525 et En. VI, 652-653, 656 ; le même écart de registres s'y manifeste, la référence à la Sibylle, v. 534, prenant alors la valeur d'une allusion humoristique, mais annonçant également les paroles d'Énée, lorsqu'il évoque pour Anna sa descente aux Enfers (F. III, 613-620).

41. La métamorphose finale d'Anna projetterait l'image de la pratique transformatrice mise en œuvre par une réécriture qui, entre les textes mobilisés successivement, prodigue un flux pérenne!

42. De la sorte, il se livre à un type de transformation que Gérard Genette nomme réduction, en notant qu'une telle démarche a pour inévitable conséquence de modifier significativement les effets propres au récit de départ (Palimpsestes, p. 263-264). Mais le poète, tout en jouant sur une forte accélération narrative, préserve l'essentiel des éléments significatifs, selon le régime de concision (op. cit., p. 271).

43. Voir Annexe 2 : la régularité du plan suivi manifeste à la fois une architecture originale, marquée par la symétrie, et une organisation propre à rappeler celle du poème virgilien.

44. On sait que le chiffre est repris à la fin de la halte en Sicile $(E n . \mathrm{V}, 726)$, bien que les Troyens aient passé un an à Carthage : la chronologie virgilienne ne saurait garantir un strict décompte.

45. L'incompatibilité a été soulignée par Danielle Porte (L'étiologie religieuse dans les Fastes d'Ovide, p. 145) ; elle l'accentue même, en situant la scène dans la septième année après la mort de Didon. Georges Devallet, qui ramène plus justement le total à cinq ans, y voit l'indice qu'Ovide a eu recours à une autre tradition («"Anne, ma sœur Anne!” ou les avatars des deux Anna dans la mythologie des Romains ", p. 410).

46. Une telle manœuvre expliquerait l'étonnant délai qu'Anna met avant de quitter Carthage, contrairement aux autres habitants qui s'enfuient dès l'arrivée des Numides. La désinvolture du récit, qui ne motive nullement cette bizarrerie, peut apparaître comme un signal indirect de la manipulation que l'écrivain opère sur la temporalité pour qu'elle cadre avec celle que l'on rencontre chez Denys d'Halicarnasse. Au contraire, Silius Italicus, fidèle aux leçons virgiliennes, quand il retraçait à son tour l'histoire d'Anna, s'est appliqué à gommer l'intervalle, ne laissant subsister que les deux ans passés dans le royaume de Battus (Pun. VIII, 54-55 et 61-62) ; ce point est souligné par Georges Devallet («"Anne, ma sœur Anne !” ou les avatars des deux Anna dans la mythologie des Romains ", p. 412).

47. On trouve un même parallélisme entre les deux vers, dont le premier, dans les deux cas, évoquant l'été, débute par l'adjectif, tertia ; alors que Virgile reprend ce mot dans l'hexamètre suivant, Ovide le remplace par une variante, dans le pentamètre, le distributif ternaque; d'autre part, comme pour attester la différence des genres, il introduit en fin de vers, avec musta lacus, une réminiscence élégiaque (Tib. I, 1, 10).

48. On décèle dans les Métamorphoses un traitement comparable à l'égard de certaines divergences entre les sources (Gilles Tronchet, La métamorphose à l'œuvre, p. 371 ss.). Déjà Felix Peeters soulignait, dans le cas des Fastes, le goût d'Ovide pour un emploi éclectique de la tradition (Les « Fastes» d'Ovide - Histoire du texte, p. 58-59).

49. Pour concilier les durées diégétiques, une échappatoire est envisageable, si l'on suppose que la venue d'Énée dans le Latium a été plus tardive qu'on ne le pense habituellement : c'est que, chez Virgile, le séjour des Troyens à Cumes n'est pas quantifié, ce qui incite le lecteur à en minimiser l'amplitude ; mais rien n'empêcherait d'imaginer un assez long intervalle séparant la descente d'Énée aux Enfers et la mort de Caiète. Seulement, le récit ovidien n'offre aucun indice allant dans ce sens.

50. L'inventaire de ces analogies a été dressé par James C. McKeown («Fabula proposito nulla tegenda meo:Ovid's Fasti andAugustanpolitics", p. 171-172), ainsi que par Danielle Porte (L'étiologie religieuse dans les Fastes d'Ovide, p. 145-149). L'enquête, affinée, sur divers détails, par des travaux ultérieurs, a été récemment reprise avec un grand soin par Nadia Manaï, dans un mémoire de master intitulé Les origines romaines dans les Fastes d'Ovide : un labyrinthe narratif; 
plusieurs indications vont lui être empruntées. Dans l'Annexe 3, les éléments narratifs que les aventures d'Anna partagent avec celles d'Énée sont récapitulés.

51. Le premier hémistiche du v. 563, Terque 'Vale' dixit ("À trois reprises, elle lui dit 'Adieu'"), conjugue, aux mêmes places, le Iamque uale ("Maintenant, adieu") de Créüse à l'adresse de son mari (En. II, 789) avec le triple effort d'Énée pour embrasser l'apparition spectrale, Ter conatus (En. II, 792), tandis que le rejet du verbe pressit (v. 564), quand Anna presse l'urne contre ses lèvres, répond au ter frustra comprensa, à propos de l'image fugitive «trois fois serrée en vain » (En. II, 792). On note aussi le commun redoublement de l'adverbe ter et, pour évoquer une présence fantomatique, le retour de la forme verbale uisa (En. II, 773 et F. III, 564). Autant d'échos très parcellaires mais qui se conjuguent.

52. Le retour de moenia, au début des v. 560 et 566, s'accompagne tantôt de l'adjectif sororia, v. 559 , tantôt du génitif sororis, v. 566 .

53. On retrouve à proximité, en début de vers, même s'il désigne le lieu d'escale ultérieur, le nom moenia (En. III, 17).

54. Comme le relève James C. McKeown, (" Fabula proposito nulla tegenda meo: Ovid's Fasti and Augustan politics », p. 171).

55. Comme l'a bien montré Danielle Porte, le choix de cette escale offre un jeu de mots implicite, relié aux vers précédents. En effet les habitants qui fuient Carthage occupée par les Numides sont comparés à des abeilles (v.555-556); or le nom latin de l'île, Melite, ressemble au nom grec de l'abeille, $\mu \varepsilon ́ \lambda \iota \tau \tau \alpha$. Et comme, dans l'Énéide, les sujets de Didon, en train de construire la ville, étaient assimilés à des abeilles au travail (I, 430-436), l'analogie s'installe en correspondance avec Virgile (L'étiologie religieuse dans les Fastes d'Ovide, p. 146). On pourrait ajouter que le doublet

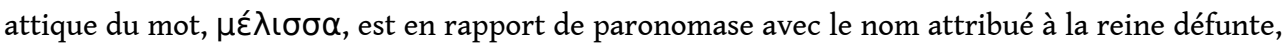
Elissa, repris juste avant par Ovide à Virgile, avec une même forme de génitif en fin de vers ( $F$. III, 553 et $E n$. IV, 335). Stephen Hinds associe la comparaison ovidienne entre les Carthaginois et les abeilles à plusieurs autres passages virgiliens, dans les Géorgiques ainsi que l'Énéide ( Generalising about Ovid », p. 14); mais leur rapport avec le passage semble moins spécifique.

56. Paul Murgatroyd y ajoute la première escale, en Thrace (Mythical and legendary narrative in Ovid's Fasti, p. 114); mais les analogies très limitées qu'il relève ne semblent pas aussi probantes que celles avec les deux épisodes suivants de l'Énéide : les anciens rapports d'hospitalité entre Priam et Lycurgue (En. III, 15) sont moins liés au contexte du voyage que ceux d'Anchise avec le roi Anius, à Délos, d'autant que la formule hospitio...uetusto (F. III, 569) emprunte au second passage un couple de vocables répartis sur deux vers, aux mêmes places (En. III, 83-84); et le fuge prononcé par la voix d'outre-tombe de Polydore (En. III, 44) cadre moins bien avec la situation d'Anna, lorsque Battus lui enjoint de fuir (F. III, 578), que le conseil des Pénates apparus à Énée, quand une épidémie se déchaîne en Crète (En. III, 160).

57. Le tua est répond au virgilien uestra est. L'insistance sur l'exiguité de l'espace qu'occupe ce royaume, battu par des flots hostiles, prélude aux menaces qui vont lancer Anna dans une fuite renouvelée (Paul Murgatroyd, Mythical and legendary narrative in Ovid's Fasti, p. 6). On peut noter que la formule correspondante, v. 568, uerberat unda, reprend les termes d'Hélénus à propos de Charybde (En. III, 423) : elle est donc susceptible d'annoncer la tempête que va subir Anna. Mais Ovide se souvient également d'un passage de l'Alexandra de Lycophron (v. 1027-1029), où l'île battue par les flots est déjà vouée à l'accueil d'exilés : symptomatiquement, l'adjectif $\Sigma$ ık $\alpha$ vò Sicanien, est remplacé par Libyci, Libyen, annonçant de manière allusive le transfert de Battus, présenté comme le souverain de Malte, au lieu de Cyrène (voir ci-dessous n. 115). De plus on s'avise que le distique (v. 567-568) est lui-même agencé comme une sorte d'îlot verbal, inscrivant en filigrane, avec un art consommé, la perspective de telles menaces : les cinq lettres et sonorités initiales du premier mot, à valeur euphorique, fertilis, reviennent dans celles de l'ultime vocable, freti, la mer, qui est au contraire associée à une violence omniprésente. La clôture ainsi réalisée figure un basculement prévisible. Dès lors, l'antithèse marquée par le voisinage entre Malte, 
présentée comme prospère, et Cosyra, une île désolée, sterili, peut être envisagée comme emblématique des revers du sort toujours proches (d'autant que l'adjectif reproduit, à part l'initiale, les sonorités et les lettres de fertilis).

58. Les ressemblances précises demeurent limitées. On distingue, à la fin du v. 591, imoque a gurgite pontus ("et, depuis les entrailles de son gouffre, le flot..."), une formulation qui rappelle diffusément, en les combinant, les fins d'En. I, 114 et 118, ingens a uertice pontus ("depuis les hauteurs, l'énorme flot...") et in gurgite uasto ("sur le vaste gouffre"), tandis que le v. 592 intègre le motif du navire qui prend l'eau (En. I, 122-123) ; dans la suite, Ovide, on l'a évoqué plus haut, puise dans le même développement le trait épique du makarismos (F. III, 597-598 et En. I, 94-96). À cet égard, Jean-Marc Frécaut relève la tonalité distanciée du second vers, où quaecumque, invoquant n'importe quelle femme, au lieu de renvoyer à telle héroïne précise, manifeste, par sa désinvolture même, ce que peut avoir de convenu le recours à ce type de figure (L'Esprit et l'humour chez Ovide, p. 124).

59. Corrélativement, les rames entrent en action (En. III, 207 et F. III, 586). Plus loin dans le récit, l'embarras qui s'empare du pilote au milieu des intempéries (v. 593-594) reprend celui de Palinure (En. III, 201-202). Au demeurant, les ressemblances du passage avec les tempêtes de l' Énéide sont nettement moins accentuées que celles avec la tornade subie, dans le livre XI des Métamorphoses, par Céyx, autre victime d'un sort impitoyable et promis non moins à la métamorphose (voir le tableau récapitulatif dressé par Eugène de Saint-Denis : Le rôle de la mer dans la poésie latine, Paris, 1935, p. 354). On perçoit quelle est la complexité des liens analogiques que ménage Ovide.

60. Comme le précise Eugène de Saint Denis, « le bâtiment est drossé au large » (Le rôle de la mer dans la poésie latine, p. 346).

61. Le concours de circonstances qui lui fait rejoindre Énée, en impliquant une étape ultérieure à la diégèse de l'Énéide, fait passer le récit, comme continuation, du régime paraleptique, appuyé sur un parallélisme avec le scénario du modèle, à une dimension proleptique, entraînant l'innovation.

62. Cette équivalence tendancielle aboutit à l'instant où Énée reconnaît Anna. Car, ainsi que le fait remarquer Danielle Porte, le v. 607, ponctué par l'exclamation que pousse Achate, offre une séquence à l'experte ambiguïté, où il est possible de lire " un clin d'œil savoureux » : Aeneas Anna est, "Énée! c'est Anna!" peut s'entendre non moins comme "Anna est Énée", ou bien l'inverse (L'étiologie religieuse dans les Fastes d'Ovide, p. 149).

63. À cela s'ajoute, affirmant la portée proleptique du récit, une allusion immédiate à l'accomplissement d'une prophétie énoncée par Jupiter dans la fin de l'Énéide: il garantissait à Junon la fusion à venir des peuples d'Ausonie avec les Troyens (En. XII, 834-840) ; c'est chose faite, quand arrive Anna (F. III, 602, où la forme verbale miscuerat, indiquant ce mélange, rappelle une insistance virgilienne, mixtum, v. 838, renforçant commixti, v. 835). Sur ce rapprochement, Giorgio Brugnoli, « Anna Perenna », p. 155.

64. Mais seul, le quid initial, d'ailleurs employé en tant qu'adverbe au lieu de pronom, est commun aux deux énoncés.

65. Grâce à la reprise du même participe, la formule aspicit errantem... Annam ("il aperçoit Anna en train d'errer", v. 605) semble fournir comme une réponse décalée, en résonance avec une partie de la question virgilienne : uidistis si quam hic errantem forte sororum ("si, par hasard, vous avez vu l'une de mes sœurs en train d'errer par ici"). On ne s'étonne donc pas que la transition narrative, qui introduit le héros virgilien dans les aventures d'Anna, s'amorce par Iam pius Aeneas... ("Désormais le pieux Énée...", F. III, 601), en désignant le personnage d'une manière, certes récurrente dans l'Énéide, mais qui, à cette place exacte dans le vers, intervient pour la première fois chez Virgile au début du passage corrélé : At pius Aeneas... ("Mais le pieux Énée...", En. I, 305). 
66. Par ailleurs, Giorgio Brugnoli associe le rivage où Énée se promène, après l'avoir reçu en dot de Lavinia, avec l'annonce, dans le prologue de l'épopée, de la venue du héros sur les rivages de Lavinium (...Lauiniaque uenit / litora..., En. I, 2-3) : l'accomplissement du destin royal se ramènerait ainsi à un mariage chanceux («Anna Perenna », p. 155). C'est déjà ce que Didon offrait vainement au héros dans la septième Héroïde (v. 149).

67. À cette perspective d'une issue menaçante va répondre la comparaison du v. 646, où Anna est assimilée à une daine terrifiée par des loups, un peu comme Didon, comparée à une biche blessée au début du livre IV de l'Énéide (v. 69-73).

68. Ses paroles de bienvenue suggèrent qu'il identifie la situation d'Anna avec la sienne, au moment où il arrivait en Afrique. En effet, les v. 621-622 rappellent nettement la conclusion de ses récits à Didon (En. III, 715) : Énée, s'adressant à la voyageuse, émet l'hypothèse qu'un dieu "t'a poussée sur nos rivages" (te nostris appulit oris); de cette action propice, il espérait être le bénéficiaire dans l'hexamètre virgilien dont Ovide reprend l'énoncé, en changeant simplement le pronom personnel et le possessif, le sujet deus étant reporté au pentamètre suivant. Mais la scène de rencontre, dans les Fastes, est marquée par l'ambivalence: en particulier, la crainte que manifeste Anna, dès qu'elle a reconnu Énée, suggère d'emblée l'intuition d'un terrible danger (v. 609-610).

69. Le recours à la forme verbale iuro, accompagnée d'un double per,marque le lien entre les passages. Divers détails sont ensuite puisés dans l'Énéide, comme la blessure de Didon que contemple celui qui en a été la cause, tout en protestant que jamais il ne s'était douté des intentions de la reine (En. VI, 450, 463 et $F$. III, 617-620).

70. C'est d'ailleurs ce qu'elle redoute, v. 610, en évoquant l'image de sa sœur par un pressentiment qui va trouver sa confirmation au v. 639, quand celle-ci lui apparaît. Dans le v. 609, la formule quos terrae quaerat hiatus ("quel gouffre dans la terre peut-elle aller chercher?"), rappelle une exclamation de Didon chez Virgile, où la reine réclame que la terre l'engloutisse, plutôt que de trahir sa fidélité à Sychée (En. IV, 24). On peut voir dans ce recoupement l'annonce pour Anna d'un sort analogue à celui de sa sœur. James C. McKeown signale qu'ainsi est préfiguré le motif amoureux qui achève l'épisode ovidien, où Énée, en suscitant les soupçons de Lavinia, cause la perte d'Anna, de même qu'il avait entraîné la mort de Didon (« Fabula proposito nulla tegenda meo: Ovid's Fasti and Augustan politics », p. 171). Cependant le souhait d'Anna au v. 609 prend rétrospectivement une valeur ironique : ce n'est pas au fond du sol, mais dans les eaux du Numicius, non plus métaphoriquement mais effectivement, qu'elle trouvera le refuge qui scellera en même temps sa disparition.

71. On retrouve ainsi, transposé, un motif de l'Énéide soulignant la nocivité des cadeaux faits par Énée à la reine, lorsque l'Amour, sous l'apparence d'Ascagne, en les lui remettant, déchaîne en son cœur la passion (En. I, 713-714).

72. Les v. 633-634, empruntant à En. IV, 67 la métaphore de la "blessure secrète" (tacitum... uulnus), qui s'appliquait à Didon, la transpose de la douleur d'être délaissée à l'aiguillon de la jalousie: "blessure fallacieuse", falsumque...uolnus, que Lavinia "enfouit dans le secret de son cœur", mente premit tacita.

73. L'adverbe furialiter, introduit par Ovide (v. 637), résume les multiples occurrences du nom furor, désignant la passion irrationnelle, dans les livres IV et VII de l'Énéide (par exemple, IV, 376 et VII, 392).

74. Voir Danielle Porte, L'étiologie religieuse dans les Fastes d'Ovide, p. 148. Au demeurant, la formulation initiale ( $F$. III, 639) combine les réminiscences, puisqu'elle se fonde aussi, de manière flagrante, sur l'intervention des Pénates de Troie, qui indiquent à Énée comment échapper à l'épidémie (En. III, 147 et 150) : la même amorce, Nox erat ("C'était la nuit"), se conjugue avec un énoncé très proche, ante torum uisa est adstare ("devant sa couche parut se dresser..."), en regard de uisi ante oculos astare ("devant ses yeux parurent se dresser..."). Plus loin, le détail de la fenêtre par laquelle se sauve Anna (fenestra en fin de vers, F. III, 643) répond à une notation de lumière 
chez Virgile, où le clair de lune se glisse par les fenêtres (fenestras à la même place, En. III, 152). Il est vrai que, dans ce passage, on le verra (p. 28), la complexité des échos excède le seul registre de l'épopée.

75. L'impératif fuge revient à la même place, dans le dactyle initial d'un hexamètre.

76. D'autant que ce qualificatif reprend la plupart des phonèmes de squalenti, renforçant ainsi la remarquable compacité d'un vers, où deux couples de mots s'emboîtent en alternant épithètes et noms. Au demeurant, tout le second hémistiche dérive de la septième Héroïde (v. 70), où Didon menaçait Énée de voir son spectre venir le tourmenter, motif issu de Virgile (En. IV, 384-386) ; Ovide y retravaillait déjà un passage de Tibulle, évoquant la jeune sœur de Némésis, morte accidentellement et dont l'ombre sanglante risquerait d'apparaître à l'amante rétive (II, 6, 38-40 ; c'est au dernier vers qu'est emprunté l'adjectif sanguinulenta). La réécriture de l'Énéide se trouve donc intriquée avec un enchaînement de références élégiaques d'autant plus savoureux que c'est bien, comme chez Tibulle, de la vision d'une sœur qu'il s'agit. Ovide ne se fait pas faute de renforcer les échos : dans le v. 639, la formule ante torum, "devant sa couche", provient de Tibulle II, 6, 38. Au contraire, quand Silius Italicus met en scène à son tour l'ombre de Didon (Pun. VIII, 164 ss.), il évite ce jeu analogique en supprimant la corrélation avec Tibulle pour privilégier les correspondances avec l'apparition d'Hector (Giorgio Brugnoli, « Anna Perenna », p. 162-163).

77. La manœuvre effectuée par Ovide peut être rapprochée de la tendancielle structure en anneau qu'il confère à l'épisode : l'ombre ensanglantée de Didon répond à l'évocation initiale de sa mort, en même temps que la disparition finale d'Anna fait pendant à celle de sa sœur, rappelée au début.

78. Déjà, la formule initiale, Nox erat, pouvait associer à la vision de Didon chez Ovide, outre celle des Pénates, celle du fleuve chez Virgile (En. VIII, 26 et $F$. III, 639). Ensuite, l'épithète de nature, corniger, "muni de cornes", reprise en début de vers (En. VIII, 77 et $F$. III, 647), rapproche les dieux en cause et débouche sur la commune immobilisation de leurs eaux, dont ils interrompent le flux (En. VIII, 87-88 et F. III, 652-653): le lien repose notamment sur le retour des adjectifs tacitus,"silencieux", et placidus, "paisible".

79. Le calme des eaux lui permet de révéler à ceux qui la cherchent qu'elle est désormais la nymphe Anna Perenna.

80. D'ailleurs, une résonance est perceptible entre cet événement et la métamorphose d'Anna : une même fin de vers en $M$. XIV, 599 et $F$. III, 647, cet hexamètre commençant par l'épithète corniger tout comme M. XIV, 602.

81. Aussi convient-il de relativiser l'opposition qu'établit Félix Peeters à propos d'Ovide "entre les sources formelles qui lui ont apporté une expression, une tournure de vers, et les sources fondamentales auxquelles il a emprunté ses thèmes" (Les « Fastes» d'Ovide - Histoire du texte, p. 50). En fait, l'examen qui précède montre que le poète conjuguait bien souvent les corrélations thématiques avec les réminiscences verbales.

82. À cet égard, les aventures d'Anna fournissent un contre-exemple à l'assertion d'Elena Merli, selon laquelle l'Énéide ne se prêtait guère à une réécriture dans les Fastes (Arma canant alii Materia epica e narrazione elegiaca nei Fasti di Ovidio, p. 54). Simplement, dans le cadre d'une œuvre aussi différente de l'épopée virgilienne, une telle réécriture ne pouvait qu'emprunter un cheminement spécifique et innovant.

83. "the very roots of Virgil's poetry" («Generalising about Ovid», p. 16).

84. Curieusement, Emily Growers, dans un développement sur les Métamorphoses, où elle associe l'histoire de l'architecture d'après Vitruve à la transformation en temple de la hutte où vivaient Philémon et Baucis, convoque l'extrait des Fastes, mais sans le relier avec celui du De architectura («Talking trees: Philemon and Baucis revisited », p. 356).

85. Robert Ling fait correspondre le type de décor "qui scandalisait Vitruve" à la seconde phase du deuxième style, illustrée notamment à Rome par les fresques de la villa Farnesina (Roman painting, p. 41-42). 
86. Commentant le passage dans le De architectura, Monica Salvadori souligne l'écart dont il témoigne entre la décoration domestique et la mise en place à Rome de solennels ensembles monumentaux. Elle rattache à juste titre la tonalité polémique à une intention idéologique, dont Ovide, précisément, se démarque : "On peut considérer que la tentative vitruvienne de moraliser l'art décoratif au nom du rationalisme de l'architecture et de la restriction du luxe fait écho à la volonté augustéenne de restauration des antiques valeurs avec le retour de la paix civile." (« Diffusion du "deuxième style" ", p. 130).

87. Le plaisir qu'éprouvent les commensaux n'est pas sans évoquer ironiquement le dépit de Vitruve, quand il doit reconnaître le goût du public pour des peintures ornementales de pure fiction. Ne peut-on supposer que les adeptes de telles décorations étaient prêts, comme lecteurs, à goûter la fantaisie ovidienne ?

88. Vitruve caractérise les représentations qu'il attaque comme des anomalies, des monstra, dont le mélange fait songer à l'être hybride dénoncé par Horace au début de l'Art poétique, où la peinture sert justement de référence à la poésie (v. 1-5). Aussi, avec cette allusion dans les Fastes, la mise en cause d'un tel point de vue par Ovide rejoint celle que l'on peut discerner dans les Métamorphoses à propos des leçons horatiennes (Gilles Tronchet, La métamorphose à l'œuvre, p. 409-411).

89. Dans certains cas, les rapports différentiels avec l'Énéide projettent sur celle-ci un éclairage indirect.

90. Il en va bien différemment pour Énée, dont l'avancée, comme l'indique Joëlle Soler, a une valeur symbolique par rapport aux connaissances qu'il accumule sur son destin (Écritures du voyage, p. 78). La fonction de narrateur qu'il assume contribue à soutenir cette image, en la fondant sur un éthos que manifestent ses réactions aux diverses péripéties du voyage (op. cit., p. 90).

91. Il est vrai que Virgile, à la différence de l'Odyssée, privilégie pour son héros le spectacle des forces monstrueuses plutôt qu'un affrontement direct avec elles (Gilles Tronchet, «Fiction de témoins et témoins de fiction: Achéménide et les Troyens (Virgile, Enéide III, 554-691)», p. 139-144). Ainsi Ovide radicalise une tendance à l'évitement des épreuves qui se manifestait déjà dans son modèle.

92. Pourtant Ovide ne s'est pas refusé à suivre le motif oraculaire dans les Fastes, avec les prophéties de Carmentis, la mère d'Évandre (I, 509-536 et VI, 537-548). La première de ces occurrences, évoquant la venue des Troyens et sa portée décisive pour l'histoire de Rome, s'intègre à une reprise plus large de l'Énéide et met l'accent sur la signification globale de cette œuvre (Bruno Poulle, «La nouvelle Énéide d'Ovide dans les Fastes (I, 461-586) », p. 67). Par contre, l'agencement du passage n'est pas corrélé, comme l'est l'histoire d'Anna, au schéma de l'épopée virgilienne : Ovide expérimente, au fil de son œuvre, des pratiques distinctes de réécriture, celle du livre I méritant de façon moins immédiate que celle du livre III la désignation de son résultat comme une "nouvelle Énéide".

93. En l'occurrence, un geste révélateur d'Anna consiste, durant la tempête, à se cacher les yeux, plutôt que de faire face à la mer démontée (F. III, 596). Au contraire, chez Virgile, le naufrage d'un des navires se produit "sous les yeux mêmes" d'Énée, ipsius ante oculos (En. I, 114).

94. Même s'ils s'absentent lors du dénouement, laissant le héros choisir le sort qu'il va réserver à Turnus.

95. On n'en trouve pas moins de sept mentions sur 110 vers, dont la première concerne les Carthaginois (v. 555), mais les six autres impliquent Anna elle-même (v. 565, 578, 579, 606, 641, avec la répétition de fuge). La prégnance d'une telle série et le fait qu'elle s'achève, avec l'impératif fuge, sur un écho reliant l'apparition de Didon à celle d'Hector chez Virgile (En. II, 289), conduisent, selon une discrète incitation ovidienne, à observer le thème de la fuite dans l' Énéide. On s'avise qu'il hante déjà le développement homologue, puisque douze occurrences concernant le héros et ses compagnons jalonnent les récits par Énée de ses voyages (En. III, 44, 
avec la répétition de fuge, $160,268,272,283,398,423,459,639$, avec la répétition de fugite, 666). La faiblesse manifeste qui caractérise Anna pourrait bien faire transparaître, en filigrane, une tendancielle fragilité inhérente au personnage virgilien.

96. Au contraire, chez Virgile, un préambule développe les préparatifs (En. III, 1-8). Quant au choix par Ovide d'une embarcation au lieu d'une flotte, on peut y voir un emblème de la réduction d'échelle qui préside à l'ensemble du récit.

97. Elles sont relevées par Paul Murgatroyd (Mythical and legendary narrative in Ovid's Fasti, p. 127).

98. Le verbe ducitur appliqué au navire (v. 599) confère tendanciellement à l'ouragan le statut paradoxal d'auxiliaire dans le cadre du voyage.

99. Au demeurant, cette indécision préfigure la suite : la venue dans le Latium, si elle constitue pour le voyage un aboutissement, est aussi l'origine de nouvelles tribulations.

100. Boris Eikhenbaum en analyse le mécanisme dans « La théorie de la "méthode formelle" », p. 51-55.

101. Voir ci-dessus.

102. "Aeneas appears as a wishy-washy, inept hero who is married to a jealous virago" (" Ovid's narrator in the Fasti », p. 43 ; voir aussi Playing with time, p. 49).

103. Elle est d'ailleurs concurrencée, au moment où il prend la parole, par une antonomase proprement ovidienne (M. XIII, 625 et XIV, 584), Cythereius heros, ("le héros, fils de la déesse de Cythère", v. 611), qui, en évoquant Vénus, la mère d'Énée, renvoie aux capacités de séducteur plutôt qu'à celles de lutteur et de fondateur.

104. Selon un sous-entendu ironique, envisagé plus haut (n. 66), son royaume est caractérisé comme provenant d'une dot (v. 603).

105. Si son nom apparaît deux fois, c'est avec la mention de cadeaux qu'elle avait faits, transmis à d'autres par Ascagne ou Énée (En. IX, 266 et XI, 74).

106. Cependant l'adjectif memores, que lui-même s'applique (v. 623), peut offrir par ailleurs un indice allusif de la mémoire textuelle à l'œuvre dans ses paroles, étant donné qu'elles rappellent, on l'a vu, plusieurs passages de l'Énéide, offrant ainsi un complément à l'occurrence du v. 553 (commentée à la note 19).

107. Dans son effort pour mettre en valeur Anna, en lui attribuant un royaume en Libye (v. 631), il l'assimile davantage encore à Didon.

108. C'est ce qu'affirme Alessandro Barchiesi (Il poeta e il principe, p. 153). Sur l'éventualité d'une tradition à laquelle renverraient les soupçons de Lavinia, voir ci-dessus n. 22 .

109. Ovide ménage dans le récit un jeu d'échos internes qui appuie cette assimilation, grâce au retour d'une identique forme, sororis, à la même place (v. 610, 624 et 632) : c'est d'abord Anna qui est prise de terreur en reconnaissant Énée, parce qu'elle craint de subir un sort semblable à celui de sa sœur ; puis c'est Énée qui la met sur le même plan que sa sœur pour la gratitude qu'il leur doit ; c'est encore lui, enfin, qui demande à Lavinia de la traiter comme une sœur. La dernière occurrence fournit à la première une sorte de confirmation ironique : le comportement d'Énée met bel et bien en danger la vie d'Anna, comme il l'a fait, d'une autre manière, pour sa sœur. En même temps, cette série préfigure le retour effectif de Didon, comme ombre (v. 639).

110. Paul Murgatroyd, lorsqu'il se penche sur les structures actantielles dans les Fastes, souligne à juste titre l'intérêt porté par Ovide aux changements dans les emplois de personnages en cours de récit, selon une subtile manipulation permettant des effets inattendus (Mythical and legendary narrative in Ovid's Fasti, p. 152-156).

111. L'ensemble des catégories actantielles, définissant des classes d'acteurs, notamment dans un récit, forme un modèle d'analyse élaboré par Algirdas Julien Greimas (Sémantique structurale, p. 172-191). Le sujet est en rapport téléologique avec un objet, concret ou abstrait, dont il vise l'obtention; l'adjuvant favorise son action, alors que l'opposant l'entrave. 
112. Les paroles que lui adresse Battus manifestent cette réduction des enjeux à la seule préservation du personnage, ainsi liée au motif de la fuite : tu fuge sospes ait ("Toi, dit-il, en fuyant, mets-toi en sûreté", v. 578). On note que l'adjectif sospes parachève un jeu d'échos, dont les termes échelonnés ponctuent l'enchaînement des circonstances : comme la bonne volonté de l'hôte (hospes, v. 570) ne peut tenir devant les menaces que fait régner la puissance (opes, v. 574) de Pygmalion, la seule issue pour demeurer sauve est la fuite.

113. Claudio Marangoni évoque une "opération d'expropriation et de refonte des matériaux virgiliens" ("operazione di esproprio e di rimodellamento dei materiali virgiliani", «Di come Ovidio sia andato alla festa di Anna Perenna ", p. 4). C'est pourquoi il peut sembler illusoire de caractériser les aventures d'Anna comme une épopée miniature : cela équivaut à privilégier une particularité de l'agencement global, tout en estompant la manière dont la réécriture entraîne ce que Gérard Genette nomme une transvalorisation, celle-ci n'étant pas inhérente au seul abrègement, mais à un déplacement concerté de l'axiologie (Palimpsestes, p. 393).

114. Plus généralement, Ovide s'intéresse dans les Fastes, comme le remarque Paul Murgatroyd, aux virtualités que présente la fonction d'adjuvant, dans la mesure où elle se prête à d'éventuels basculements, introduisant des circonstances inattendues. C'est ainsi que, dans l'épisode ultérieur, la vieille Anna, en faisant croire à Mars qu'elle seconde ses efforts pour séduire Minerve, frustre le dieu (Mythical and legendary narrative in Ovid's Fasti, p. 154). D'un autre côté, certains opposants peuvent se convertir en auxiliaires, au moins à tel moment du récit, comme on l'a vu pour la tempête.

115. Un tel contraste entre l'attitude et le statut du personnage coïncide avec le déplacement qu'opère Ovide, en faisant de lui le souverain de Malte, et non le fondateur de Cyrène, identité que rétablira Silius Italicus (Pun. VIII, 57). Certes, on l'a vu, les besoins de l'homologie avec les voyages d'Énée impliquaient pour Anna de s'arrêter dans une île, mais ils n'exigeaient pas d'assigner ce nom au monarque local. Il est vrai que le choix du poète, grâce à l'homonymie, permet d'intégrer une allusion à la patrie de Callimaque, prédisposant ainsi, en regard du modèle épique, la référence à une démarche poétique d'autre sorte, celle où s'inscrivent les Fastes, dans la lignée des Aitia: Alessandro Barchiesi considère ainsi que Battus est l'emblème d'une distance envers les arma, les combats, qui caractérisent l'épopée (Il poeta e il principe, p. 13) ; il a été signalé plus haut que ce transfert s'appuie justement sur un écho avec un autre poète alexandrin, Lycophron (n. 55).

116. Ainsi, l'aide fournie retrouve l'ambiguïté de celle qu'Anna prodiguait chez Virgile à sa sœur. 117. On note l'humour du narrateur ovidien dans l'usage de la fonction testimoniale, l'authenticité du dénouement forgé par le poète étant relativisée par creditur, "croit-on", ramenée à une simple opinion; cet effet se prolonge, grâce au modalisateur uisa est ("sembla-til", v. 653), à propos des révélations finales de la nymphe. Sur cette manière de mettre en question les récits d'origine dans les Fastes, voir Carole Newlands, "Ovid's narrator in the Fasti », p. 33 .

118. "Roman refugium: refugee narratives in Augustan versions of Roman prehistory", p. 87-88: non seulement la situation finale du personnage n'a rien d'enviable, mais elle ne répond en aucun cas à sa volonté (contrairement, par exemple, à la transformation qu'implore Daphné dans les Métamorphoses, I, 547).

119. Certes, la mise en place de l'aition est censée justifier cette conversion d'Anna en Anna Perenna.

120. L'apaisement optimiste, qui renvoie chez Ovide au prologue décrivant les réjouissances en l'honneur d'Anna Perenna, diffère en tout point du pathétique marquant l'achèvement du poème virgilien, avec l'impitoyable exécution de Turnus par Énée, qui culmine dans un dernier vers évoquant l'âme du vaincu, lorsqu'elle abandonne à regret son corps (En. XII, 952).

121. Anna croit alors percevoir la sous-jacente présence de sa sœur, impression prémonitoire de l'instant où l'ombre de celle-ci la visite. Le retour de plusieurs vocables établit une indéniable 
correspondance : au est...uisa du v. 564, répond en chiasme le uisa est du v. 639 ; et la reprise de soror par sororis, en fin de vers, se conjugue avec une commune mention de la chevelure, comas, v. 562 , étant rappelé par coma, à la même place, v. 640. Les neuvième et dixième distiques en partant du début sont ainsi corrélés au neuvième en partant de la fin.

122. Outre les recoupements avec la fin de la lettre, qui ont été examinés plus haut (p. 9-10), l'évocation par Didon de son propre exil, lorsqu'elle abandonne Tyr et les cendres de Sychée ( $H$. VII, 115) trouve un corrélat en $F$. III, 559 et 563 ; on note aussi le retour de moenia en début de pentamètre ( $H$. VII, 120 et $F$. III, 560), ou encore l'emploi du vocable thalamis, à propos du mariage refusé à Iarbas (H. VII, 124 et $F$. III, 553).

123. On l'a noté précédemment, $n .76$.

124. Paul Murgatroyd signale, de pair avec ce rapprochement, le retour de la même fin de vers dans l'Art d'aimer (I, 527), à propos d'Ariane abandonnée par Thésée (Mythical and legendary narrative in Ovid's Fasti, p. 261). Cependant, on va le voir, une seconde corrélation avec le début d' Am. I, 5, témoigne d'un rapport spécifique, dont il n'y a, semble-t-il, pas trace pour l'Art d'aimer. Du reste, dans le recueil, figurent deux occurrences analogues, renvoyant aussi à Corinne (Am. III, 1,51 et III, 7, 81).

125. Au lieu d'une fin de pentamètre, c'est un début d'hexamètre qu'occupe l'énoncé analogue audacem faciebat amor ("l'amour lui donnait de l'audace", M. IV, 96). Le ipse en surplus dans les Fastes, conjugué avec la variation de temps pour le verbe, rend plausible une adaptation métrique à partir des Métamorphoses plutôt que le contraire. En effet, du point de vue du rythme, la formulation des Fastes pouvait être intégrée dans celles-ci, sans autre aménagement que la substitution d'amor à timor, alors que l'inverse était impossible. L'analyse procure donc, pour les passages concernés, un plausible indice d'antériorité pour les Métamorphoses par rapport aux Fastes.

126. Ovide, qui reprend l'ablatif, lui rattache ingénieusement l'adjectif humili, comme répondant à son opposé chez Tibulle, excelsa.

127. L'homologie avec Tibulle, qui est la plus nette, associe le renvoi à une élégie avec l'évocation de la mort, comme pour accréditer une élaboration intermédiaire entre les domaines de la poésie érotique et de l'épopée.

128. Voir annexe 4. On remarque en début de pentamètre un même type de verbe modalisateur, marquant une réserve de la narration quant à la véracité de l'événement (creditur équivalant à dicitur), et, dans les deux cas, introduisant un couple d'infinitifs parfaits. Certes, les anecdotes ne sont pas identiques, puisqu'llia n'est pas victime d'un rapt: c'est elle qui, désespérée, se jette dans le cours d'eau, et le dieu tutélaire la sauve.

129. Le lien se fonde sur la commune mise en relief de hanc, pour désigner le personnage féminin,et la mention finale des flots (undis) ; en outre, le verbe rapuisse, en $F$. III, 647, répond à l'adjectif rapidis (d'autant que le mot se retrouve en entier grâce à la fin de l'adjectif qui précède, tumidis (voire cupidis, selon une variante des manuscrits). Quant au second infinitif, occuluisse, en F. III, 648, il provient d'un autre passage de la même élégie, où le poète, avant d'aborder l'histoire d'Ilia, évoquait plus brièvement divers autres exemples de fleuves amoureux (Am. III, 6, 32).

130. Il est vrai que les formulations diffèrent. Mais l'adjectif tumidis, qui se rapporte aux yeux "gonflés" d'Ilia, est réutilisé dans le v. 595, où, sous la forme tumidas, il s'applique aux flots marins. Or ce vocable fait partie d'une formule qui, dans les aventures d'Anna, rapproche l'évocation de la tempête et celle du Numicius au cours impétueux : tumidas...undas, v. 595, a pour correspondant tumidis...undis, v. 647 (si du moins l'on admet cette leçon plutôt que celle de cupidis...undis). Alors, le v. 647 apparaît comme presque intégralement forgé à partir d'éléments tirés de l'élégie. Seule, l'épithète de nature corniger a une source virgilienne.

131. "Anna Perenna », p. 156 : il ne s'appuie pas sur les autres recoupements avec l'élégie, qui non seulement confortent son point de vue, mais donnent une importance particulière à cette référence ; pour sa part, il relie également la notation avec la tenue de Didon chez Virgile, quand 
la reine invoque les puissances infernales (En. IV, 518). Ce dernier rapprochement, qui est moins net, dans la mesure où les situations diffèrent considérablement, était déjà proposé par Danielle Porte; mais celle-ci, attribuant à Énée le nudo...pede, voyait là une manière pour Ovide de suggérer une analogie du héros avec Didon, en tant qu'hôte (L'étiologie religieuse dans les Fastes d'Ovide, p. 147). De son côté, E. H. Alton, n'envisageant pas la possibilité qu'Anna soit impliquée, rejetait carrément la leçon nudo, comme relevant d'un registre inapproprié au roi qu'était devenu Énée : il proposait domino en guise de correction (« Problems in Ovid's Fasti », p. 146) ; le souci de convenance présupposé en ce cas s'accorderait mal avec l'approche distanciée dont Ovide fait preuve envers la figure du héros virgilien.

132. Outre la récurrence de nudo...pede, on constate que le participe errantem (v. 605) dérive de errabat et que le "chemin écarté", secretum...iter, suivi par Anna (v. 604) répond sémantiquement aux lieux solitaires, loca sola, où errait Ilia; ailleurs dans les Fastes, Proserpine, juste avant son rapt, est évoquée de manière analogue, errabat nudo per sua prata pede (" elle errait, pieds nus, dans les prairies familières ", IV, 426 ; cette judicieuse référence est due à l'un des rapporteurs de la revue Dictynna).

133. Sur la filiation épique du motif, qui se rattache au chant XI de l'Odyssée, avec l'histoire de Tyro, rappelée chez Ovide juste avant l'histoire d'Ilia (Am. III, 6, 43-44), voir Catherine Connors, « Ennius, Ovid and the representations of Ilia », p. 102 et 109.

134. Telle est notamment l'opinion de Danielle Porte, qui invoque au surplus l'attrait du parallélisme ainsi obtenu entre les deux hémistiches (L'étiologie religieuse dans les Fastes d'Ovide, $\mathrm{p}$. 142-143).

135. Ainsi, pour la seconde fois, après le passage de l'Art d'aimer (III, 39-40) signalé plus haut (n. 35), le nom d'Anna Perenna s'avère pour Ovide l'occasion d'un rapport surdéterminé avec les emplois de termes apparentés dans ses œuvres antérieures. Les fils de l'analogie s'entrecroisent pour stimuler une inventivité qui cultive les coïncidences.

136. "Ovid, from image to narrative : Amores 1.8 and 3. 6 ", p. 18 (peut-être force-t-elle un peu la note, quand elle envisage la rivière comme "la personnification de la mauvaise poésie": il s'agirait plutôt d'incarner une ampleur incompatible avec le genre que pratique le poète).

137. Ainsi intervient le basculement narratif, "narrative reversal", diagnostiqué par Barbara Weiden Boyd à propos des Amours : les implications renvoyant au poète et à la poésie tendent à y prendre le pas sur les motifs de l'intrigue amoureuse (Ovid's literary loves, p. 138).

138. Ce constat rejoint le diagnostic de Fabio Stok: il analyse cette démarche comme un équilibre complexe associant les aspects de l'élégie et de l'épopée («L'alternativa dei Fasti», p. 68 ; voir aussi Geraldine Herbert-Brown, Ovid and the Fasti, p. 7).

139. L'ambition nouvelle qu'assument les vers élégiaques, appliqués à une œuvre plus vaste, s'affirme notamment, dans les prologues de deux livres (II, 3-4, avec la métaphore d'un navire, et IV, 3, où Vénus rappelle au poète la ténuité de ses compositions antérieures). La transgression des frontières génériques qu'elle induit est commentée par Stephen Hinds ("Arma in Ovid's Fasti ", p. 82-86). En particulier, il caractérise les aventures d'Anna comme un "flirt avec les normes du genre épique" (loc. cit., p. 108), ce qui, bien sûr, n'entraîne nulle adéquation obligée du récit aux principes de l'épopée.

140. L'ambiance élégiaque est même susceptible d'agir sur un personnage issu de l'épopée comme Lavinia: quand elle interprète les nombreux cadeaux d'Énée pour Anna comme les preuves d'une liaison cachée (v. 635-636), elle fait d'un motif épique (les dons liés à l'hospitalité) une lecture élégiaque, en prenant le héros troyen pour le riche amant, le diues amator des Amours $(\mathrm{I}, 8,31)$.

141. Elle est nommée Silvia, mais le nom d'Ilia est employé à plusieurs reprises dans le reste des Fastes.

142. Barbara Weiden Boyd, Ovid's literary loves, p. 214-218; elle note malgré tout que, dans les deux cas, Ovide s'inspire du songe où, dans les Annales d'Ennius, l'ombre d'Énée apparaissait à Ilia 
(transmis par Cicéron, De diuinatione, I, 40-41) : dans Am. III, 6, le rôle salvateur dévolu à un fleuve (Ennius, Ann. 46, ed. Warmington) est attribué par le poète non au Tibre pour Romulus et Rémus, mais à l'Anio pour leur mère; dans F. III, le décor entourant l'héroïne rappelle celui de la vision chez Ennius, notamment la présence de saules (v. 17 et Ann. 36). Voir aussi Elena Merli, Arma canant alii - Materia epica e narrazione elegiaca nei Fasti di Ovidio, p. 44 : elle souligne l'atténuation de la tonalité par rapport à la référence épique, en parlant d'un epyllion; Alessandro Barchiesi estimait déjà que le récit illustrait dans les Fastes un climat "sub-epico" (Il poeta e il principe, p. 54). 143. Si l'on songe que, d'après Servius (Ad Aen. VI, 773), Ilia était présentée par Ennius comme la fille d'Énée, la proximité entre les deux personnages se renforce d'autant.

144. Comme le souligne Carole Newlands, «Transgressive acts : Ovid's treatment of the Ides of March », p. 325.

145. Plus loin dans le livre III, le dieu lui-même consent à retirer son casque pour se faire l'émule de Minerve et s'intéresser à des œuvres pacifiques (v. 171-176). Il est vrai, comme le signale avec humour le récit, qu'il garde sa lance à la main. Stephen Hinds souligne la tension thématique ainsi ménagée par Ovide : elle conduit vers la passion, presque élégiaque, de Mars pour la déesse, sachant cependant que celle-ci est désignée comme porteuse d'armes tout comme lui (v. 681) et qu'à l'issue, le dieu se retrouve bel et bien désarmé («Arma in Ovid's Fasti », p. 98-100). Entre temps, à propos du culte des Saliens, Mars est éclipsé au profit de Jupiter, dont le débat avec Numa conduit au don de l'ancile (v. 369-378) : la seule mention du dieu guerrier survient de façon incidente au début de l'épisode, v. 259 ; corrélativement, comme le montre Fabio Stok, un jeu intertextuel détourne sur Numa, le rappel du développement où Ennius, dans ses Annales, célébrait l'avénement de Romulus, fils de Mars, comme héros fondateur (« Lo spettacolo degli ancilia », Nunc teritur nostris area maior equis - Riflessioni sull'intertestualità ovidiana - $i$ Fasti, $\mathrm{p}$. 74-78).

146. Tel est le jugement de Carole Newlands (« Transgressive acts: Ovid's treatment of the Ides of March", p. 328). Elle en vient à prendre l'ensemble de l'épisode, associé à l'ambiance carnavalesque des fêtes en l'honneur d'Anna Perenna, comme une critique moqueuse de l'Énéide ( loc. cit., p. 330) : ce diagnostic ne tient pas assez compte de la minutie avec laquelle Ovide a procédé dans sa lecture de Virgile, témoignant ainsi d'une considération envers l'œuvre qui excède l'approche du caricaturiste. La tendance ludique de la réécriture se manifeste avec délicatesse, à travers le gauchissement des motifs virgiliens. Mieux vaut donc analyser la démarche ovidienne comme révélatrice d'une instabilité constitutive des valeurs (loc. cit., p. 320).

147. Mentionnée par James C. McKeown, «Fabula proposito nulla tegenda meo: Ovid's Fasti and Augustan politics », p. 180, et Paul Zanker, Un'arte per l'impero, p. 79-80 ; d'après ce dernier, la vulgarisation $d u$ symbolisme politique, en pénétrant dans la sphère privée, s'accompagne souvent de ce qu'il nomme une intériorisation, amenant les grandes figures mythiques à illustrer par analogie le statut personnel des individus ; mais leur réception n'est pas unilatérale et l'usure des images conduit à jouer avec elles, voire à se jouer d'elles.

148. Paul Zanker souligne la diffusion de ce motif dès 28 avant notre ère (Un'arte per l'impero, $\mathrm{p}$. 85). Nul doute que l'Énéide et son héros y aient contribué par la suite.

149. Michael Von Albrecht montre combien est équilibré le rapport du poète aux œuvres de son prédécesseur, avec une attitude critique et transformatrice mais exempte de tout dénigrement (« Ovidio », p. 909).

150. "Si licet et fas est: Ovid's Fasti and the problem of free speech under the Principate », p. 7. Selon lui, Ovide aurait pêché par optimisme en croyant qu'une liberté de ton était effectivement permise au début du Principat et surtout en ne percevant pas l'évolution ultérieure (loc. cit., p. 4). 151. On peut parler, à la suite de W. R. Johnson, d'une forme d'ironie constitutive, dans la relation distante que les Fastes entretiennent avec les coutumes et un calendrier sur lequel s'étend la mainmise d'Auguste ("The desolation of the Fasti», p. 11-13). Mais, plutôt que de projeter dans cette attitude une sorte de fuite existentielle face à un monde où l'écrivain ne se 
reconnaîtrait plus, il convient de la relier à la persistance d'une expérimentation poétique, dont témoignaient déjà les œuvres antérieures d'Ovide. En somme, il n'est pas nécessaire de fournir un arbitrage interprétatif entre une révolte et une déférence du poète face au régime et à son idéologie : thématiquement une œuvre comme les Fastes est susceptible d'apporter sa caution à l'une comme à l'autre voie. Ce sont les effets de sens produits par l'agencement des textes et les relations qu'ils entretiennent avec d'autres, selon une réécriture complexe et virtuose, qu'il importe de mettre en évidence.

152. Alessandro Barchiesi souligne que, par sa nature même, la poétique d'Ovide se démarquait d'un discours augustéen visant à l'unification (Il poeta e il principe, p. 277-278).

153. Charles Robert Phillips insiste sur la déconstruction ainsi opérée, notamment quand Ovide fait vaciller la référence au fatum, aux destins censés garantir, depuis les origines de Rome, l'avènement légitime de l'ordre augustéen («Rethinking Augustan poetry », p. 805-806). Ainsi le poète met en scène le désordre potentiel d'une tradition variable, alors que le régime se veut restaurateur d'un ordre universel; en résulterait une radicale "absence de signification" ("meaninglessness", loc. cit., p. 815). Cependant, étant donné que, bien souvent, est dramatisée la pluralité des traditions diverses, on préférera la formule de Carole Newlands, évoquant des "significations qui se font concurrence à propos du passé" ("competing meanings about the past", Playing with time, p. 80). Une telle stratégie, plus nette encore dans les deux derniers livres des Fastes, tend à rendre problématique la pertinence d'une autorité univoque.

154. Byron Harries rejette à bon droit l'alternative qui divise les critiques entre les caractérisations d'Ovide comme pro- ou bien anti-augustéen ; la démarche du poète est complexe, dans la mesure où elle est liée à des effets sous-jacents d'ironie ("Causation and the authority of the poet in Ovid's Fasti », p. 164 et 166).

155. Sur la place de cette œuvre comme référence culturelle et comme point d'appui d'une cohésion politique, dont Ovide, par ses expérimentations poétiques, est amené à se démarquer, voir Giorgio Brugnoli et Fabio Stok, Ovidius $\pi \alpha \rho \omega \delta \eta ́ \sigma \alpha \varsigma$, p. 9-10.

156. D. C. Feeney, «Si licet et fas est: Ovid's Fasti and the problem of free speech under the Principate », p. 14.

157. C'est rétrospectivement qu'il en est fait mention ( $F . \mathrm{V}, 569$, comportant malgré tout un écho à III, 710).

158. Il est notable que cette déesse se substitue à la protectrice attitrée de César, Vénus, telle qu'Ovide lui-même la met en scène dans les Métamorphoses, où elle n'emmène au ciel que l'âme du dictateur (XV, 843-846).

159. Une correspondance de détail confirme le rapprochement : Vesta elle-même désigne César, en tant que pontifex maximus, comme son prêtre, sacerdos (v. 699), tout comme Silvia était nommée sa servante, ministra (v. 47).

160. En outre, le schématisme du récit évoquant l'action de la déesse revêt une tonalité quelque peu désinvolte si l'on songe au lien spécial qu'Auguste, devenu grand pontife à son tour, en 12 avant notre ère, entretenait avec son culte: la propre maison de l'empereur, sur le Palatin, abritait une image de Vesta (Geraldine Herbert-Brown, Ovid and the Fasti, p. 66 ss.). C'est plus haut dans le livre III qu'Ovide souligne la proximité entre la déesse et Auguste, attribuant à celui-ci le titre de sacerdos; il le désigne en même temps comme un descendant d'Énée (v. 425), alors qu'il va offrir peu après du héros troyen, avec les aventures d'Anna, une image des plus pâle!

161. Stephen Hinds insiste, en forçant parfois un peu la note, sur la présentation négative de Romulus dans les Fastes («Arma in Ovid's Fasti », p. 124 ss. notamment).

162. La mésaventure d'Ilia trouve ainsi un corrélat supplémentaire. Byron Harries rapproche à juste titre les deux passages ("Causation and the authority of the poet in Ovid's Fasti », p. 176).

163. Un écho à l'Énéide établit un lien avec les aventures de la première Anna ; une formule pathétique, évoquant les affres de la passion qu'endure Didon, appliquée à l'amour de Mars pour 
Minerve, revêt, en féminisant le dieu, une implication satirique (F. III, 682 et En. IV, 1-2 ; voir Paul Murgatroyd, Mythical and legendary narrative in Ovid's Fasti, p. 111).

164. L'épisode correspond à un fait historique, intervenu en 205 avant notre ère, au moment où régnait l'angoisse de la guerre contre Carthage et Hannibal. Le poète, évoquant une Rome au faîte de sa puissance, élude ce contexte, alors qu'il prend bien soin de mentionner le chef troyen.

165. Les analyses ne s'arrêtent guère sur cet écho, mais établissent plutôt la liaison entre le voyage d'Ino et celui d'Évandre avec Carmentis (Elaine Fantham, « The role of Evander in Ovid's Fasti », p. 166, qui voit là un effet de symétrie dans le bloc de six livres ; Parshia Lee-Stecum, « Roman refugium : refugee narratives in Augustan versions of Roman prehistory », p. 86).

166. "Connecting the disconnected», p. 173-174 et 201; Alessandro Barchiesi indiquait déjà cette piste (Il poeta e il principe, p. 69).

\section{RÉSUMÉS}

Pour expliquer l'origine des fêtes d'Anna Perenna, Ovide recourt à la sœur de Didon, Anna, telle qu'elle apparaissait dans l'Énéide. Il invente pour elle des tribulations qui reprennent le schéma épique des errances d'Énée. Mais la réécriture détourne le modèle vers des enjeux décalés qui mettent en cause les valeurs de l'épopée, tout en ménageant une hybridation avec l'élégie. L'analyse minutieuse du détournement narratif ainsi opéré conduit à préciser la poétique des Fastes, à montrer en particulier comment la composition et la structure de l'œuvre elles-mêmes peuvent déterminer les rapports qu'elle entretient avec l'idéologie augustéenne.

\section{INDEX}

Mots-clés : élégie, épopée, idéologie augustéenne, poétique, réécriture 